\title{
Benign mimics of prostatic adenocarcinoma
}

\author{
Kiril Trpkov \\ Department of Pathology and Laboratory Medicine, Calgary Laboratory Services and University of Calgary, \\ Rockyview General Hospital, Calgary, AB, Canada
}

\begin{abstract}
Benign mimics present either as common challenges in daily routine practice or may cause diagnostic dilemmas because some are less commonly seen and one may be less familiar in recognizing them. There are a multitude of mimics of prostatic adenocarcinoma, which may represent normal gland structures, benign proliferations, atrophic lesions, hyperplastic or metaplastic changes, and inflammatory processes. Some of them are preferentially found in certain anatomic areas of the prostate, either confined to the prostate, or outside of the gland. Various benign mimics of prostatic carcinoma may be also evaluated based on their morphologic similarity to Gleason patterns 3-5 of prostatic adenocarcinoma. Most of the mimics are easily recognizable in larger specimens, such as TUR of the prostate or radical prostatectomy specimens, but they may pose diagnostic problems when the evaluation is done on limited tissue, such as needle-core biopsies or if prostate specimens are infrequently encountered in practice. Therefore, before signing out a report with a diagnosis of prostatic carcinoma, pathologists should carefully consider and rule out the various benign lesions that may mimic carcinoma. This is particularly relevant in the current prostate biopsy practice which relies on using extended biopsy core templates. The awareness and familiarity with the characteristic features of the mimics and judicial use of additional ancillary tests, including immunohistochemistry can prevent overdiagnosis and falsepositive interpretation. This review provides a contemporary update on the broad spectrum of the benign prostatic lesions that can mimic prostate adenocarcinoma, outlines their key morphologic and immunohistochemical diagnostic features, and provides a diagnostic, pattern-based approach in establishing a correct diagnosis and distinguishing them reliably from prostatic adenocarcinoma.

Modern Pathology (2018) 31, S22-S46; doi:10.1038/modpathol.2017.136
\end{abstract}

\section{Introduction}

Reliable and accurate diagnosis of many benign mimics depends not only on the morphologic skills of the pathologists, but also on the proper technical handling and processing of the biopsies and other prostate specimens. The diagnostic prowess of the pathologist will be significantly increased if several preanalytical pitfalls can be avoided, particularly regarding core biopsy handling, excessive core fragmentation, technical tissue processing, including poor fixation, overstained or poorly stained slides, and excessively thick biopsy core sections. Distinguishing the benign mimics from prostatic adenocarcinoma is of paramount importance, because a false-positive, incorrect diagnosis may lead to serious patient care and medicolegal consequences.

Correspondence: Dr K Trpkov, MD, FRCPC, Department of Pathology and Laboratory Medicine, Calgary Laboratory Services and University of Calgary, Rockyview General Hospital, 700714 Street, Calgary, AB T2V 1P9, Canada.

E-mail: kiril.trpkov@cls.ab.ca

Received 30 June 2017; revised 25 August 2017; accepted 26 August 2017
This is particularly important when one deals with limited tissue specimens, such as needle core biopsy. In broad terms, benign mimics of prostate cancer may represent constituents of normal anatomy, benign glandular proliferations, various patterns of atrophy, hyperplasia, metaplasia, and inflammatory processes (Table 1). The most common adenocarcinoma-like benign lesions of prostate consist predominantly of small gland proliferations, such as atrophy, partial atrophy, postatrophic hyperplasia, adenosis (or atypical adenomatous hyperplasia), and basal cell hyperplasia. Some have found that partial atrophy and benign crowded glands (Figures 1a and b) were the most common benign mimics of prostatic carcinoma in needle biopsy specimens. ${ }^{1}$ Some of the mimics may be found within the prostate gland, while some are typically found exclusively outside of the gland or at the gland periphery. The benign mimics may also be distinguished based on their similarities with the different morphologic patterns of cancer. In keeping with the recommendations of the International Society of Urologic Pathology (ISUP) Consensus Conferences on Gleason grading of prostatic carcinoma in 2005 and $2014,2,3$ benign cancer mimics may generally 
Table 1 Classification of the benign mimics of prostatic carcinoma based on the anatomic origin or the type of process they represent.

\begin{tabular}{ll}
\hline Normal anatomy & Hyperplasia \\
\hline $\begin{array}{l}\text { Seminal vesicles } \\
\text { Cowper's glands } \\
\text { Paraganglia }\end{array}$ & $\begin{array}{l}\text { Basal cell hyperplasia } \\
\text { Verumontanum gland hyperplasia } \\
\text { Clear cell cribriform hyperplasia }\end{array}$ \\
Atrophy & Metaplasia \\
\hline Simple & Nephrogenic metaplasia \\
Partial atrophy & Mucinous metaplasia \\
Bostatrophic hyperplasia & \\
\hline Adenign proliferations & Inflammatory process \\
Sclerosing adenosis & $\begin{array}{l}\text { Chronic inflammation } \\
\text { Granulomatous prostatitis }\end{array}$ \\
\hline
\end{tabular}

represent: (i) individual and well-formed glands (small acinar proliferations) that mimic Gleason pattern 3; (ii) cribriform, fused and poorly formed glands, similar to Gleason pattern 4; and (iii) solid and individual cell (non-glandular) proliferations, mimicking Gleason pattern 5 (Table 2). The benign proliferations forming small glandular (or acinar) formations mimicking Gleason pattern 3 cancer, comprising individual and well-formed neoplastic glands, are the most common ones. The spectrum and the differential diagnosis of the benign mimics of prostate cancer in various types of specimens have been covered in several previous reviews and studies. ${ }^{1,4-8}$

The objective of this review is to provide a contemporary update on the spectrum of the benign prostatic lesions that can mimic prostatic adenocarcinoma and to outline their key morphologic and immunohistochemical diagnostic features. We hope that this will help pathologists develop a patternbased approach in recognizing the benign mimics of cancer and appreciate the main diagnostic pitfalls in establishing a correct diagnosis, which will ultimately increase the diagnostic accuracy in reliably recognizing and correctly diagnosing the benign carcinoma mimics.

\section{Atrophy (Simple Atrophy, Postatrophic Hyperplasia, Partial Atrophy)}

Atrophy of the prostate is a common and age-related process, although it has been documented as early as the second decade of life. ${ }^{9}$ The main morphologic variants of atrophy include: (a) simple atrophy; (b) postatrophic hyperplasia (also labeled 'lobular atrophy' by some); and (c) partial atrophy. Simple atrophy can also show cyst formation. ${ }^{10}$ Sclerotic atrophy, another morphologic category characterized by prominent fibrotic component has
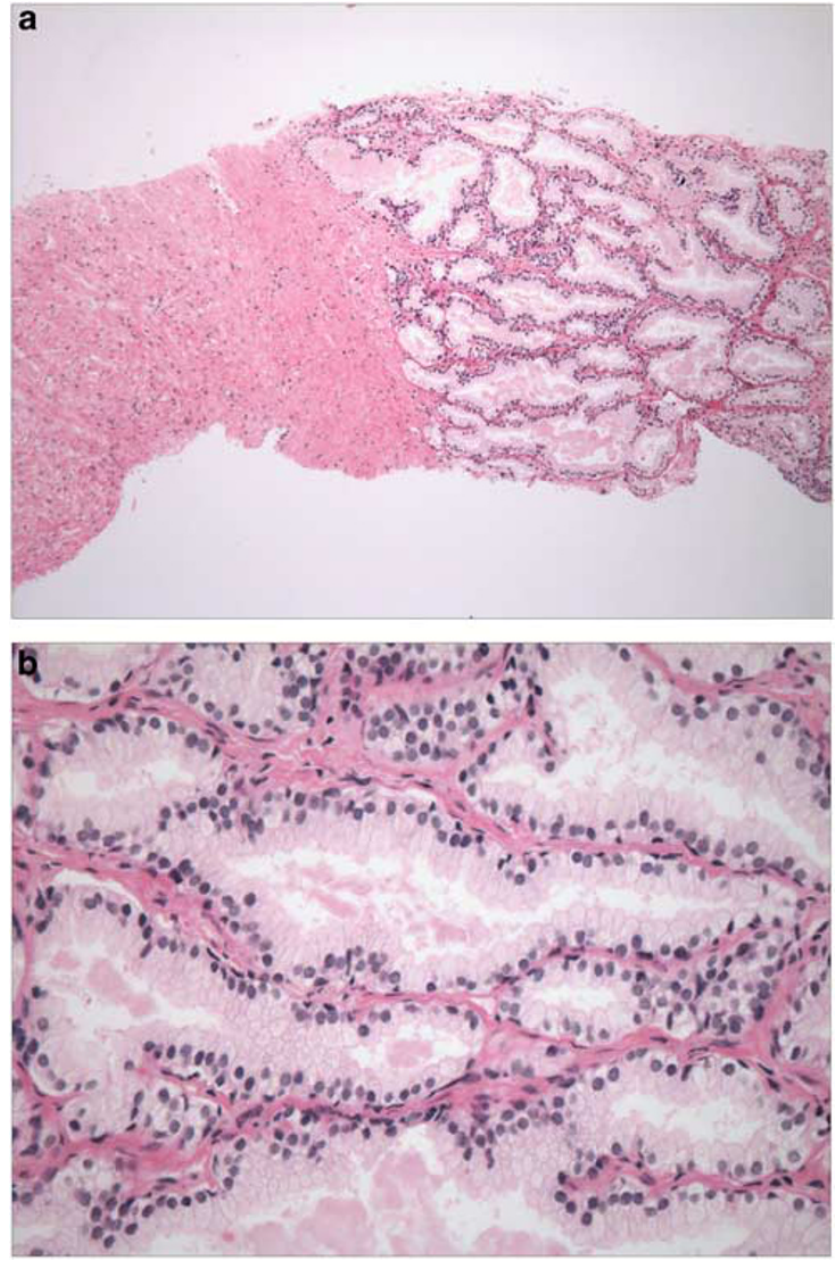

Figure 1 Benign crowded glands. Benign crowded glands showing back-to-back arrangement may be a reason for concern, particularly on needle biopsy (a). At low magnification a sharp and noninfiltrative border can be seen (left), as well as an irregular, nonuniform shape of the acini. Two-cell-layer lining of the glands can be focally appreciated at higher magnification, along with the bland nuclei without macronucleoli (b). The luminal border is not sharp and straight, but undulating and feathery, as typically seen in the benign glands. Although focal luminal granular secretions are present, there are no crystalloids and blue mucin.

also been documented in the early literature. ${ }^{11}$ Combined or admixed patterns of atrophy are frequently encountered.

Simple atrophy. Simple atrophy is the most common morphologic variant and in general, the term 'atrophy' is typically used to designate simple atrophy. The pathogenesis of atrophy is still unknown, but atrophy is often associated with an accompanying inflammation. ${ }^{12,13}$ The inflammatory infiltrates, which are mostly chronic, are often found within and around the foci of atrophy; in contrast, inflammation is infrequently seen in the foci of prostatic adenocarcinoma. There is no conclusive evidence that patients with atrophy have an increased risk of either harboring or developing 
Table 2 Benign mimics may show similarities with prostatic carcinoma Gleason patterns 3-5

\begin{tabular}{lcc}
\hline Pattern 3 & Pattern 4 & Pattern 5 \\
\hline Atrophy & Basal cell hyperplasia & Granulomatous prostatitis \\
Partial atrophy & Clear cell cribriform hyperplasia & Malakoplakia \\
PAH & Paraganglion \\
Adenosis & Xanthoma \\
Sclerosing adenosis & \\
Basal cell hyperplasia & \\
Mucinous metaplasia & \\
Nephrogenic metaplasia & \\
Seminal vesicle & & \\
Cowper's glands & & \\
Mesonephric hyperplasia & & \\
Distorted rectal tissue & &
\end{tabular}

prostatic carcinoma or precursor lesions. ${ }^{14,15}$ Atrophy is typically found incidentally in various prostatic specimens. Although atrophy is common in the peripheral zone, it may also be seen in the central zone and in the transitional zone. Atrophy of the benign prostatic glands can also occur after treatment with antiandrogens and radiation, which typically results in a diffuse (or global) glandular atrophy.

On low power examination, atrophy demonstrates lobular and noninfiltrative growth and simple atrophy and postatrophic hyperplasia have a basophilic (or blue) appearance on H\&E, caused by the scant cell cytoplasm and crowded, bland-appearing nuclei, with increased nucleus-to-cytoplasm ratios. The glands usually show irregular or angulated shapes and are generally the same size or slightly smaller than the adjacent nonatrophic glands. One of the key morphologic hallmarks of atrophy is the reduction of the cytoplasmic volume, resulting in almost complete absence of the luminal epithelial cells (Figures 2a and b). The cells usually have small nuclei and inconspicuous nucleoli. The nuclei often extend to the full height of the lining cells. Focal nucleolar prominence may sometimes be seen in the acinar cells, representing a reactive change mostly seen in the diffusely inflamed areas. ${ }^{13}$ Cystic dilatation can be seen in areas of simple atrophy, but more typical foci of simple atrophy are often found adjacent to or in continuity with the cystic areas. The term cystic atrophy is applied to glands that exhibit sharp luminal borders and generally lack infoldings (Figures 2c and d). The cysts may appear more crowded when arranged back to back.

Postatrophic hyperplasia. Postatrophic hyperplasia is a variant of atrophy that consists of crowded and relatively compact clusters of small, atrophic acini, often arranged around a larger and dilated 'feeder' duct (Figures 2e and f). $(16,17)$ The acini are lined by cuboidal secretory cells that typically lack apical and lateral cytoplasm, have small to mildly enlarged nuclei and show an increased nucleus-to-cytoplasm ratio when compared with the adjacent benign epithelial cells. The smaller glands are often clustered in a grape-like manner around the larger duct, imparting a lobular appearance to the lesion, which some have referred to as 'lobular atrophy'. The stroma surrounding postatrophic hyperplasia may be sclerotic or elastotic. Postatrophic hyperplasia may rarely be considered a mimicker of prostatic adenocarcinoma, primarily because of its crowded appearance, and the key diagnostic features include the retained lobular architecture with the identification of the feeder duct, the overall basophilic appearance, and often the finding of sclerotic peripheral areas.

Partial atrophy. Partial atrophy may be the most problematic of all variants of atrophy because it may be confused with low-grade prostatic carcinoma. ${ }^{18,19}$ Although the foci of partial atrophy may retain the lobular architecture, they may also show more disorganized and irregular growth (Figures 3a and b). Partial atrophy also lacks the basophilic appearance typically seen in simple atrophy and postatrophic hyperplasia. The glands in partial atrophy typically display pale and clear cytoplasm, and the nuclei of the secretory cell often appear spaced apart, with scant apical cytoplasm and abundant pale lateral cytoplasm (Figure 3c). The nuclei are small and show cylindrical or elongated shapes. The nucleoli are typically inconspicuous, but occasionally they can be more prominent, although not as prominent as the macronucleoli of the malignant cells. ${ }^{20}$ The basal cells may be inapparent or quite patchy. The foci of partial atrophy are frequently seen adjacent to or admixed with the foci of simple atrophy, which may aid in their recognition. Fine luminal granular secretions may often be seen, but luminal crystalloids or blue mucin are usually lacking.

Although the basal cells are typically present in the atrophic lesions, in partial atrophy they may be difficult to appreciate. In such cases, the stains for high molecular weight cytokeratin (HMWK), such as $34 \beta E 12$ and Cytokeratin 5/6, or the nuclear p63 staining may be helpful in highlighting the basal 

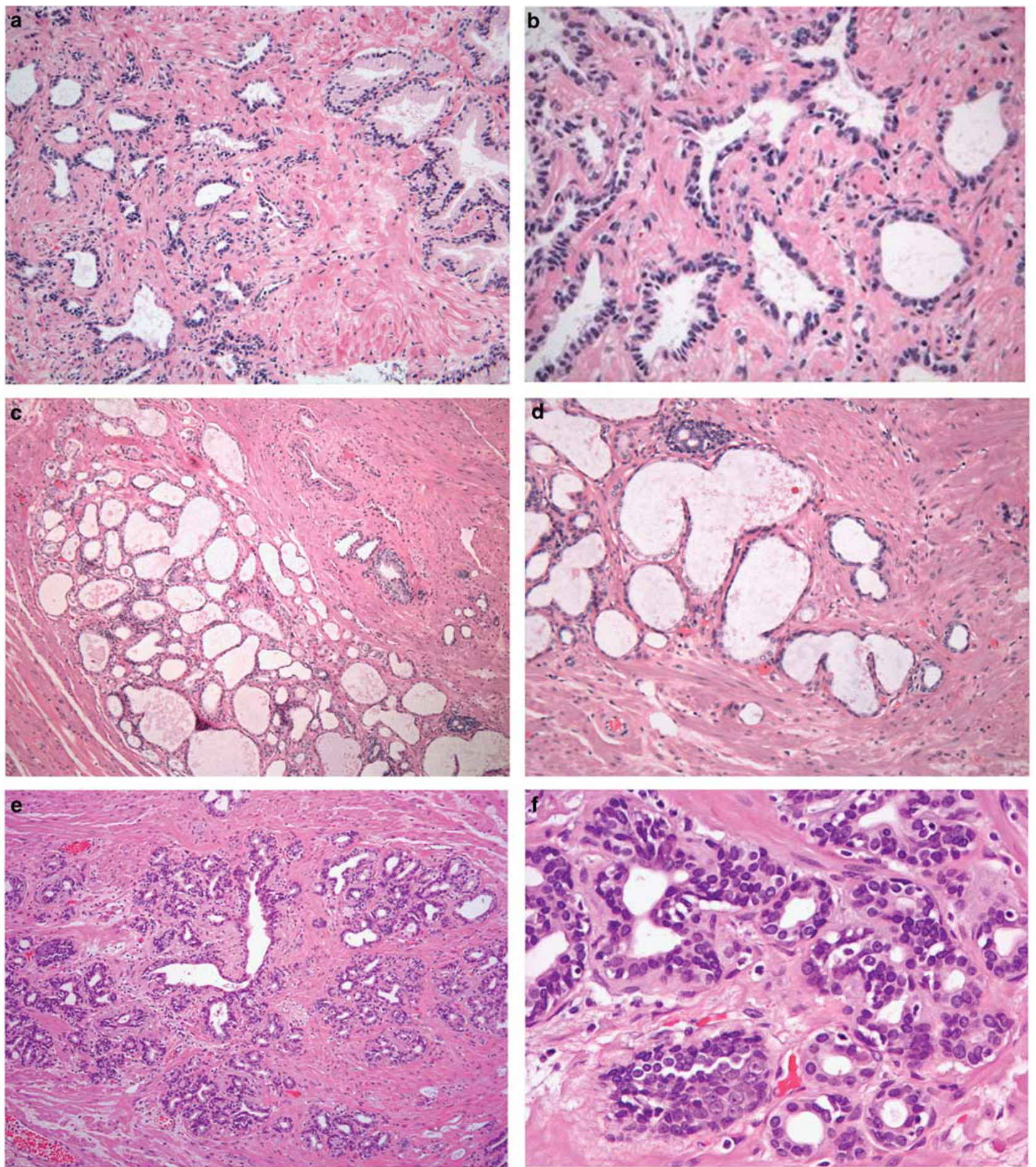

Figure 2 Various morphologic patterns of atrophy. Atrophy or simple atrophy is composed of glands generally showing non-infiltrative growth that have a basophilic (or blue) appearance on H\&E (a); normal acini can be seen on the right. The cells have scant cytoplasm and bland-appearing nuclei, with increased nucleus-to-cytoplasm ratio and inconspicuous nucleoli (b). Simple atrophy can also show cyst formations (cystic atrophy), which can focally be prominent with more crowded glands arranged back to back (c,d). The glands exhibit sharp luminal borders and generally lack infoldings. Postatrophic hyperplasia is a variant of atrophy that consists of crowded and relatively compact clusters of small, atrophic acini, often arranged around a larger dilated 'feeder' duct (e). The acini are lined by cuboidal secretory cells that typically lack apical and lateral cytoplasm, have small to mildly enlarged nuclei and show an increased nucleus-tocytoplasm ratio (f). 

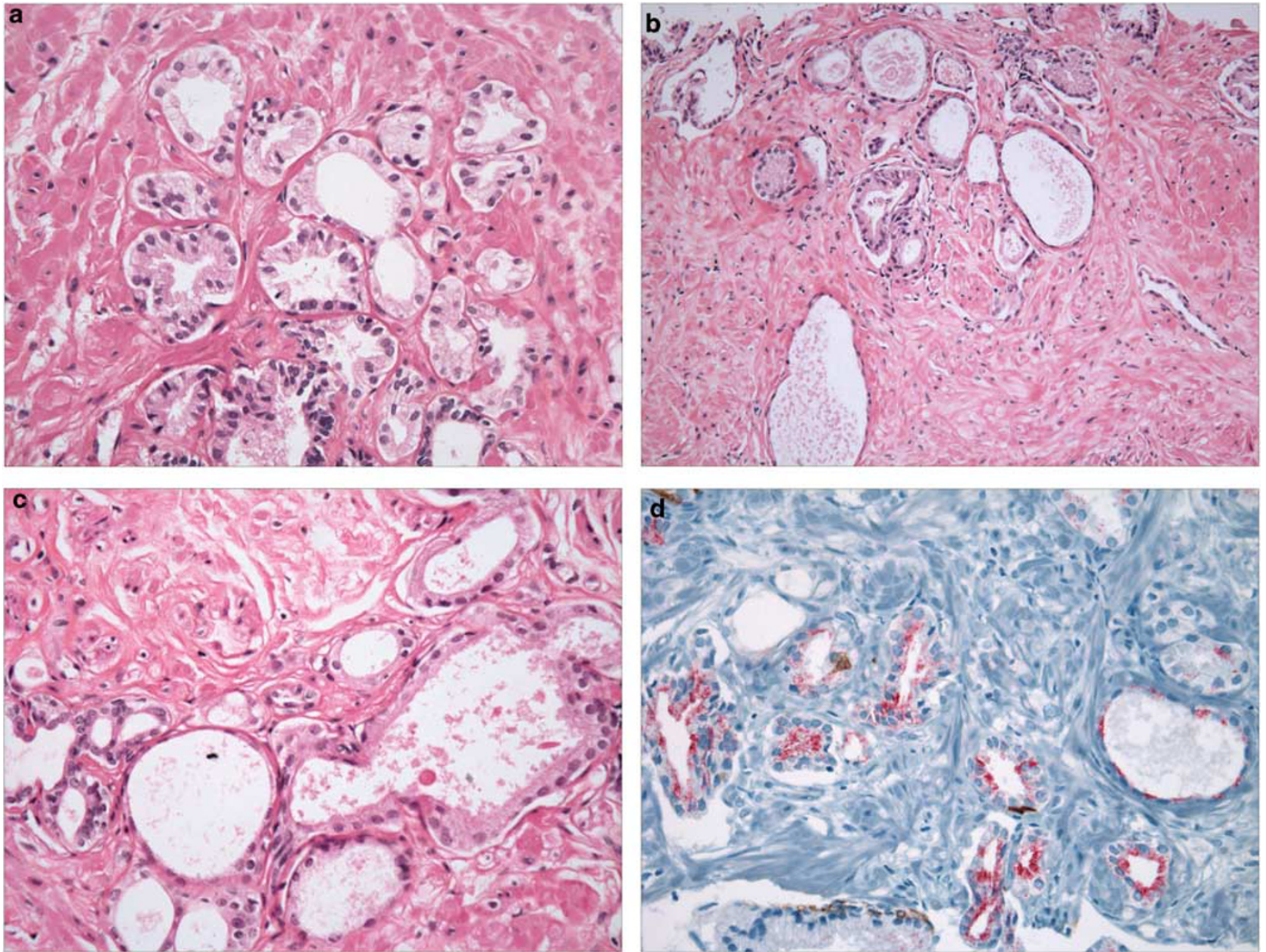

Figure 3 Partial atrophy. Partial atrophy often shows lobular and non-infiltrative growth comprising pale and bland appearing acini (a). The glands can vary in size and show more disorganized and irregular growth (b). The acini usually show pale to clear cytoplasm, and the nuclei often appear spaced apart, with scant apical cytoplasm and abundant pale lateral cytoplasm. The nuclei are bland and the nucleoli are typically inconspicuous (c). In the foci of partial atrophy not all atrophic glands will demonstrate basal cells by HMWK; among the positive glands, the staining can also be incomplete, frequently marking only scattered basal cells (d). AMACR may also show focal reactivity in some of the acini of partial atrophy, further mimicking the immunoprofile of prostatic carcinoma.

cells and confirming the benign nature of the glands. ${ }^{18,19,21}$ Simple atrophy and postatrophic hyperplasia typically show complete and circumferential staining with the basal cell antibodies and they are usually negative for alpha-methylacyl-coenzyme A racemase (AMACR). However, immunohistochemistry is only rarely needed to recognize these lesions. In contrast, partial atrophy typically shows patchy and often very focal immunoreactivity for the basal cell markers (Figure 3d). In the foci of partial atrophy not all atrophic glands will demonstrate basal cells; among the positive glands, the staining can be incomplete, frequently marking only rare basal cells. The absence of basal cells in some of the glands in the partial atrophy should not be misinterpreted as a microfocus of prostatic carcinoma. AMACR may also be frequently positive in the foci of partial atrophy, further mimicking the immunoprofile of prostatic carcinoma. ${ }^{21,22}$ When individual glands show a 'malignant' profile (negative HMWK, positive AMACR), one should always evaluate the totality of all morphologically similar glands, instead of focusing on the 'malignant' profile of individual glands or small gland clusters.

Differential diagnosis. Prostatic adenocarcinoma with atrophic features, ${ }^{23,24}$ and low-grade or transition-zone carcinomas $^{25}$ (Gleason pattern 3) can be distinguished from atrophy based on the infiltrative growth, frequent component of usual acinar carcinoma, amphophilic or eosinophilic (not basophilic) cytoplasm, greater degree of cytologic atypia including prominent nucleoli, and complete lack of basal cells, shown by immunohistochemistry. Atrophic glands may frequently exhibit corpora amylacea, but they typically do not contain luminal crystalloids, wispy blue mucin and granular secretions, which are frequent luminal contents of the 
neoplastic glands. Atrophic acini that exhibit visible reactive nucleoli within the areas of inflammation (particularly acute inflammation) can be confused with prostatic adenocarcinoma exhibiting atrophic pattern $^{23,24}$ or flat type of high-grade prostatic intraepithelial neoplasia (PIN). AMACR may also be focally positive in the acini exhibiting reactive changes. However, the nucleoli are typically more prominent both in atrophic prostatic adenocarcinoma and in high-grade PIN with flat pattern than in atrophy.

\section{Adenosis (Atypical Adenomatous Hyperplasia)}

Adenosis, or atypical adenomatous hyperplasia, is one of the most common benign lesions that may be confused with prostatic adenocarcinoma, and is predominantly seen on needle biopsy or on TURP. ${ }^{26-29}$ The lesion morphologically simulates low-grade prostatic carcinoma of the transition zone (Gleason pattern 3). It has been postulated that many of the originally described Gleason pattern 1 cancers, seen in larger specimens prior to the use of immunostains, may have actually represented adenosis. Adenosis has a predilection for the transition zone and the periurethral area. Accordingly, it has been identified more frequently on TURP (1.5 to $19.6 \%$ ) than on needle core biopsy (less than $1 \%$ ); ${ }^{1}$ it is also present in about 20 to $60 \%$ of radical prostatectomies.

It is characterized by a localized proliferation of crowded and small, closely-spaced glands, arranged in circumscribed clusters or nodules. Adenosis may particularly cause diagnostic challenges in needle core biopsy specimens, because it is generally seen less often in biopsies and it is frequently sampled incompletely (Figures 4a and b). Adenosis may show a pseudoinfiltrative growth in limited needle biopsy cores, with only a portion of the whole lesion represented. Although adenosis usually shows worrisome and crowded architecture, the cytology generally appears bland and benign, blending with the morphology of the adjacent benign glands. Although the biologic significance of adenosis is unclear, it is considered a benign lesion which carries no increased risk for prostatic carcinoma or high-grade PIN. In support of its benign nature, TMPRSS2-ERG gene fusion and ERG protein expression have not been found in adenosis of the prostate. ${ }^{30}$

At scanning magnification, adenosis is characterized by lobular proliferation of crowded, small glands exhibiting back to back growth, with absent or minimal infiltration into the surrounding stroma (Figures $4 \mathrm{a}-\mathrm{C}$ ). Within the glandular nodule, there is often an admixture of larger and more irregular acini with papillary infoldings, which share identical nuclear and cytoplasmic features as the smaller glands. A rare, non-circumscribed variant of adenosis, labeled 'diffuse adenosis of the peripheral zone', was also described. ${ }^{31}$ At higher magnification, the cells show minimal cytologic atypia, and often contain abundant pale to clear cytoplasm and benign-appearing nuclei with inconspicuous nucleoli (Figures 4b and d). The glands typically show a fragmented or patchy basal cell layer, which can be difficult to appreciate on light microscopy. Corpora amylacea are commonly found in the adenosis in contrast with the prostate cancer. Although the nucleoli of the cells in adenosis may be up to medium-size and typically inconspicuous, in some cases occasional more prominent nucleoli can also be seen. ${ }^{32}$ Focal luminal crystalloids, dense secretions and rarely blue mucin can also be found, which may raise a suspicion for prostatic carcinoma, although a complete constellation of suspicious findings is rare.

By immunohistochemistry, the glands of adenosis typically show discontinuous and patchy basal staining for HMWK and p63, although some acini within the focus can be completely negative, which should not be misinterpreted as evidence of prostatic adenocarcinoma (Figure 4e). Thus, one should interpret the absence of basal cells of the individual glands strictly in the context of the uniformly benign morphology observed in the whole lesion. AMACR can also be positive in up to a third of the cases of adenosis, which can be another pitfall (Figure 4f). ${ }^{21,33}$ The biologic significance of the expression of AMACR in a subset of adenosis cases is unclear, as this protein is otherwise highly expressed in prostatic carcinoma.

Differential diagnosis. Adenosis may be misdiagnosed as prostatic carcinoma (Gleason pattern 3), particularly on limited needle biopsy tissue. In contrast to adenosis, adenocarcinoma has a more irregular and infiltrative growth and exhibits more atypical and high-grade cytology. The most important features distinguishing adenosis from prostatic adenocarcinoma include its:

- circumscribed and noninfiltrative growth,

- absence of significantly enlarged nucleoli throughout the lesion,

- presence of small, crowded glands with similar cytoplasmic and nuclear features as seen in the adjacent benign glands, and

- presence of fragmented and patchy basal cell layer.

\section{Sclerosing Adenosis}

Sclerosing adenosis of the prostate is a rare lesion that is largely restricted to the transition zone and is typically found on TUR performed in older males presenting with urinary obstruction symptoms. ${ }^{34-36}$ Sclerosing adenosis is exceptionally rarely seen in needle biopsies, potentially leading to overdiagnosis of prostatic carcinoma. ${ }^{37}$ Sclerosing adenosis is 

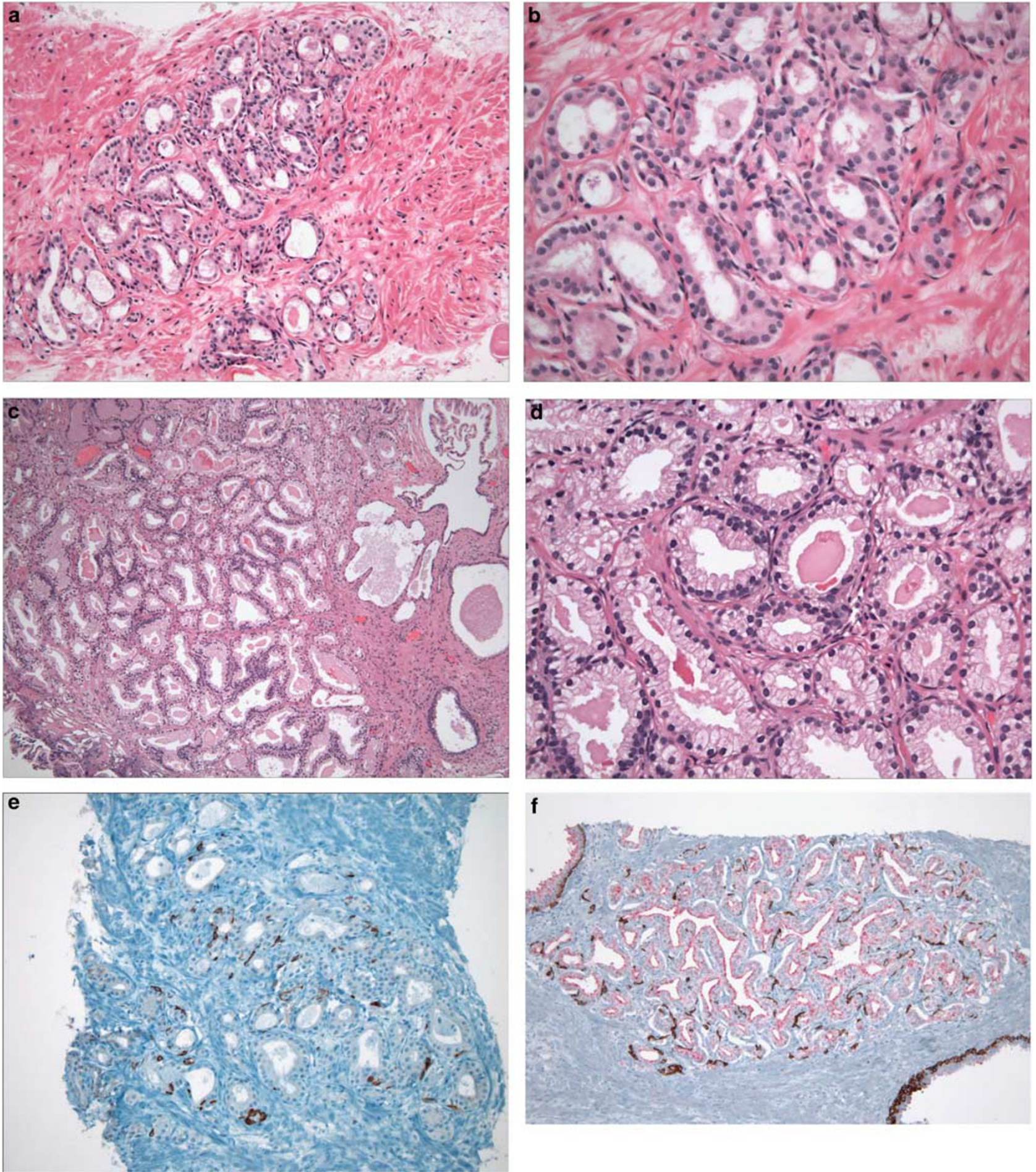

f

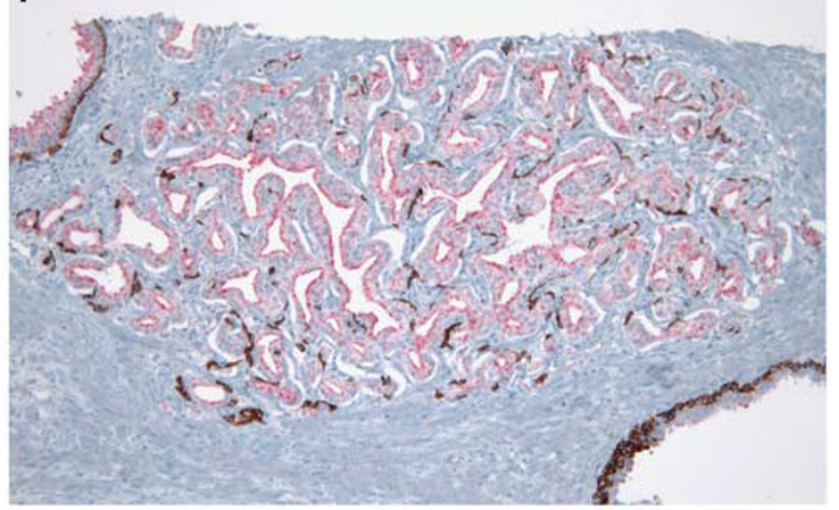

Figure 4 Adenosis. Adenosis is a localized proliferation of crowded and small acini, arranged in circumscribed clusters or nodules. This is an example on needle core biopsy (a). Although adenosis shows worrisome architecture, the cytology generally appears bland with benign small glands exhibiting back to back growth (b). Adenosis can also be rarely seen in TUR specimens (c). Focal luminal crystalloids and dense eosinophilic secretions can also be found in adenosis, as illustrated in this example (d), but a complete constellation of suspicious findings is rare. On immunostains, the glands of adenosis typically show discontinuous and patchy basal staining for HMWK (e), although some acini within the focus can be completely negative. AMACR can be positive in up to a third of adenosis cases, mimicking a malignant immunoprofile (f). 

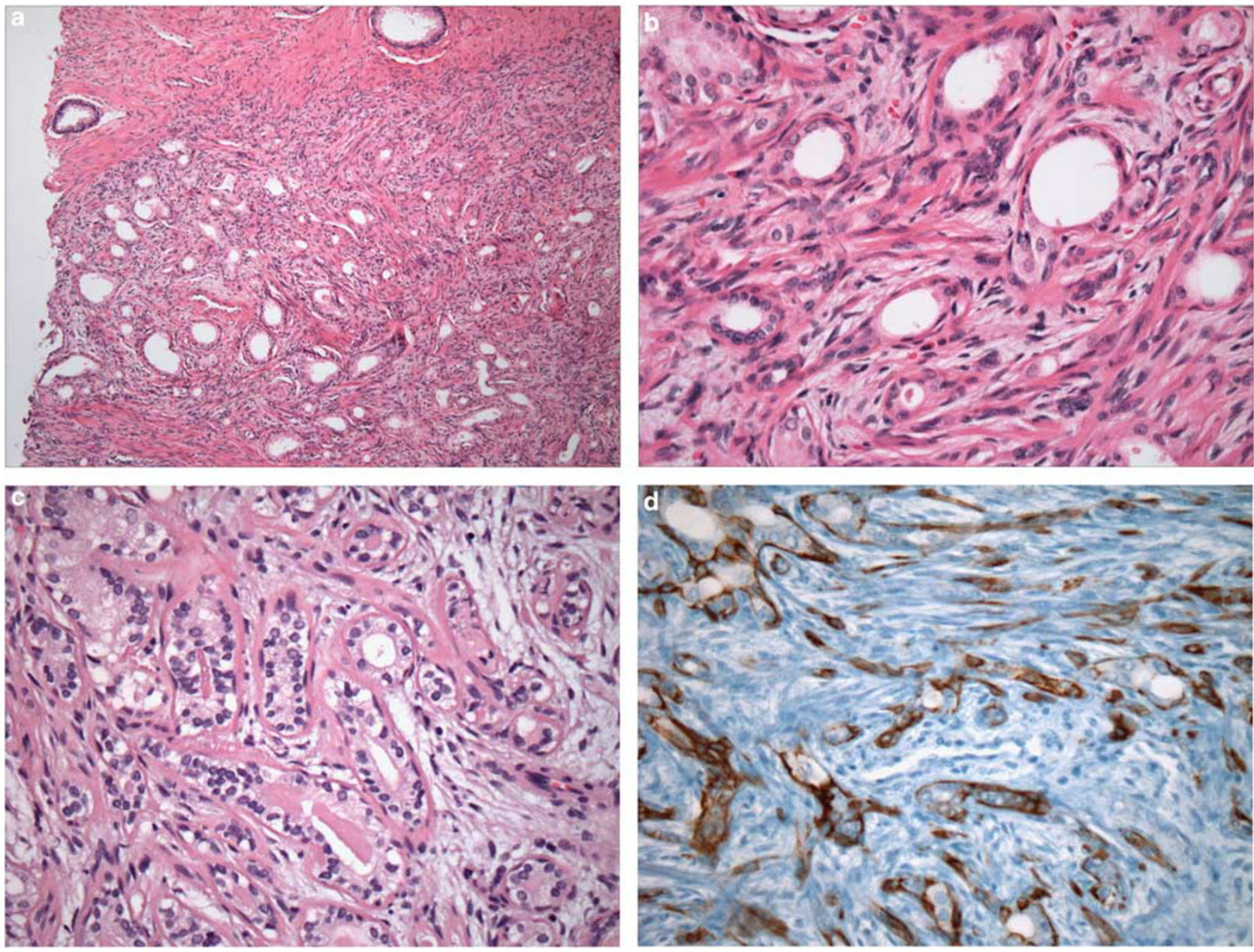

Figure 5 Sclerosing adenosis. Sclerosing adenosis is a relatively circumscribed proliferation of small acini, in a background of cellular spindle-cell stroma (a). It is characterized by well-formed acini, similar to those seen in adenosis, as well as occasional poorly formed glands and even single cells, embedded in a cellular and often edematous spindled stroma, lacking pleomorphism or mitotic figures. The stroma may also show myxoid features $(\mathbf{b}, \mathbf{c})$. Some acini are lined by thickened hyalinized stroma, resembling basement membrane (c). The basal cells and the stromal cells demonstrate myoepithelial differentiation and show coexpression of both muscle-specific actin and HMWK (Cytokeratin 5/6), as shown (d).

considered a metaplastic proliferation arising from the basal cells, with no known malignant potential.

Sclerosing adenosis represents a circumscribed proliferation of small acini, set in a background of cellular spindle-cell stroma showing myoepithelial differentiation. It is characterized by well-formed, small- to medium-sized acini, similar to those seen in adenosis, as well as occasional poorly formed glands and even single cells, embedded in a cellular and often edematous spindled stroma, lacking pleomorphism or mitotic figures (Figures $5 a$ and b). The stroma may also show myxoid features. The proportion of stroma and glands can be variable. The cells lining the acini display moderate amount of clear to eosinophilic cytoplasm. The basal cell layer may be focally prominent and hyperplastic, particularly in the acini lined by thickened hyalinized stroma at the periphery, resembling basement membrane (Figure 5c). There is usually no significant cytologic atypia in the epithelial cells or the stromal cells, but some cases may show moderate atypia. The basal cells in sclerosing adenosis have been shown to contain abundant microfilaments with prominent dense bodies, in keeping with myoepithelium. Myoepithelial cell differentiation is present in the basal cells and in the spindle-cell stroma. Rare examples of this lesion have demonstrated more significant nuclear atypia, mitotic figures and prominent nucleoli mimicking prostatic carcinoma, and have been labeled 'atypical sclerosing adenosis' ${ }^{38}$ In these cases, the diagnosis may require the aid of immunostains; they however have demonstrated the same benign course as typical sclerosing adenosis.

The basal cells and the stromal cells in sclerosing adenosis demonstrate myoepithelial differentiation and show coexpression of both HMWK (or p63) (Figure 5d) and muscle-specific actin (MSA). S-100 protein is also positive in these cells. Spindled cells coexpress MSA and S-100 (which is usually less prominent) and can also express HMWK. MSA is 
however not expressed in the normal prostatic glands. ${ }^{34-37}$ The acinar cells in sclerosing adenosis are PSA and PSAP positive. AMACR overexpression has not been reported in sclerosing adenosis.

Differential diagnosis. The key features in distinguishing sclerosing adenosis from prostatic carcinoma is the presence of distinctive cellular stroma in a relatively circumscribed lesion of small size. The recognition of the rim of thickened hyalinized stroma, resembling basement membrane can also be helpful. Immunohistochemistry for HMWK and MSA can be useful in problematic cases to document the myoepithelial differentiation of the basal and the spindle cells.

\section{Basal Cell Hyperplasia}

Basal cell hyperplasia (BCH) is typically seen focally in cases of benign prostatic hyperplasia, and is found usually in TURs from the transition zone. ${ }^{39}$ It can also be found in the peripheral zone of the prostate and it may also be encountered in needle biopsies and radical prostatectomies. ${ }^{40-42}$ When this lesion is florid and infiltrative it may mimic prostatic carcinoma and may present diagnostic problems, particularly in limited needle biopsy cores. ${ }^{40} \mathrm{BCH}$ may also be found in association with atrophy and squamous metaplasia, as part of the spectrum of reactive changes in the benign prostatic glands in patients treated by anti-androgen therapy.

$\mathrm{BCH}$ is usually characterized by nodular and localized expansion of uniform, round to elongated glands, typically demonstrating basophilic appearance. Less often BCH can demonstrate an infiltrative growth pattern, resembling Gleason pattern 3 adenocarcinoma (Figures 6a-d). BCH may demonstrate several morphologic patterns including complete (solid appearing) and incomplete BCH. A complete $\mathrm{BCH}$ pattern is characterized by solid nests of basal cells with lack of luminal cell differentiation. The incomplete pattern is characterized by the presence of residual small lumina lined by secretory cells with clear cytoplasm, surrounded by multiple layers of basal cells, which expand away from the lumen. The $\mathrm{BCH}$ may also demonstrate infiltrative acinar growth, resembling Gleason pattern 3 and cribriform (or pseudocribriform) growth, resembling pattern 4 prostate cancer (Figures 6e and f); a mixture of patterns can also be seen. However, in all morphologic variants the basal cells are dark with scant cytoplasm and display round to oval, or spindled, hyperchromatic nuclei. The proliferating basal cells may show irregular arrangement and usually appear 'piled up' with two or more cell layers present. The nucleoli are often indistinct, but sometimes they can be more prominent and easily visible, which may mimic either high-grade PIN or prostatic carcinoma. $\mathrm{BCH}$ frequently contains well-formed, lamellar microcalcifications (Figure 6c) in the lumina and also intracytoplasmic eosinophilic globules (Figures 6b-e); intraluminal crystalloids can also be rarely found. ${ }^{39,42}$ In some cases, BCH may demonstrate more prominent cribriform (or pseudocribriform) morphology, resembling cribriform pattern of prostatic carcinoma, luminal dense eosinophilic secretions, blue mucin, crystalloids, rare mitoses, or prominent nucleoli, features that may raise a question about possible prostatic carcinoma, particularly if found in a limited biopsy specimen. However, often these features are admixed with the more typical morphology of BCH that facilitates the diagnosis. Regardless of the pattern or the variable morphologic features present, BCH is not associated with adverse outcome and does not carry an increased risk for either concomitant or subsequent development of prostatic adenocarcinoma. The very rare basaloid carcinoma of the prostate, can be distinguished from BCH by their diffuse and infiltrative architecture, the presence of extraprostatic extension, perineural invasion, necrosis and stromal desmoplasia, all of which are lacking in BCH. The immunostains, which are generally unnecessary, show the same phenotype as seen in the normal basal cells: strong reactivity for HMWK and p63, and weak, focal reactivity for PSA and PSAP. AMACR is typically negative in BCH.

Differential diagnosis. BCH with prominent nucleoli or with cribriform growth can be distinguished from prostatic adenocarcinoma by the multilayering of the nuclei, frequent presence of solid cell nests, distinct basophilia, and the strong immunoreactivity for the basal cell markers. BCH with prominent nucleoli can be also sometimes difficult to distinguish from high-grade PIN. The main distinguishing features include the recognition of a the multilayered basophilic cells extending away from the lumen (rather than proliferating toward the lumen), with somewhat irregular (not perpendicular) arrangement, and the frequent finding of focal solid cell nests. If needed, immunohistochemical demonstration of the basal cells can confirm the diagnosis of BCH. BCH may also need to be distinguished from the exceedingly rare basal cell and adenoid cystic carcinomas. Basal cell carcinoma consists of variably sized solid nests, cords, or trabeculae with peripheral cell palisading, while adenoid cystic carcinoma consists of infiltrative cribriforming nests often showing necrosis, accompanied by dense or myxoid stromal reaction. Both often extend into periprostatic tissue, seminal vesicles, or bladder neck muscle.

\section{Clear Cell Cribriform Hyperplasia}

Clear cell cribriform hyperplasia is usually seen in TUR specimens removed from patients presenting with urinary obstructive symptoms and is considered by some to be part of the spectrum of benign prostatic hyperplasia. ${ }^{43,44}$ This lesion is formed by 

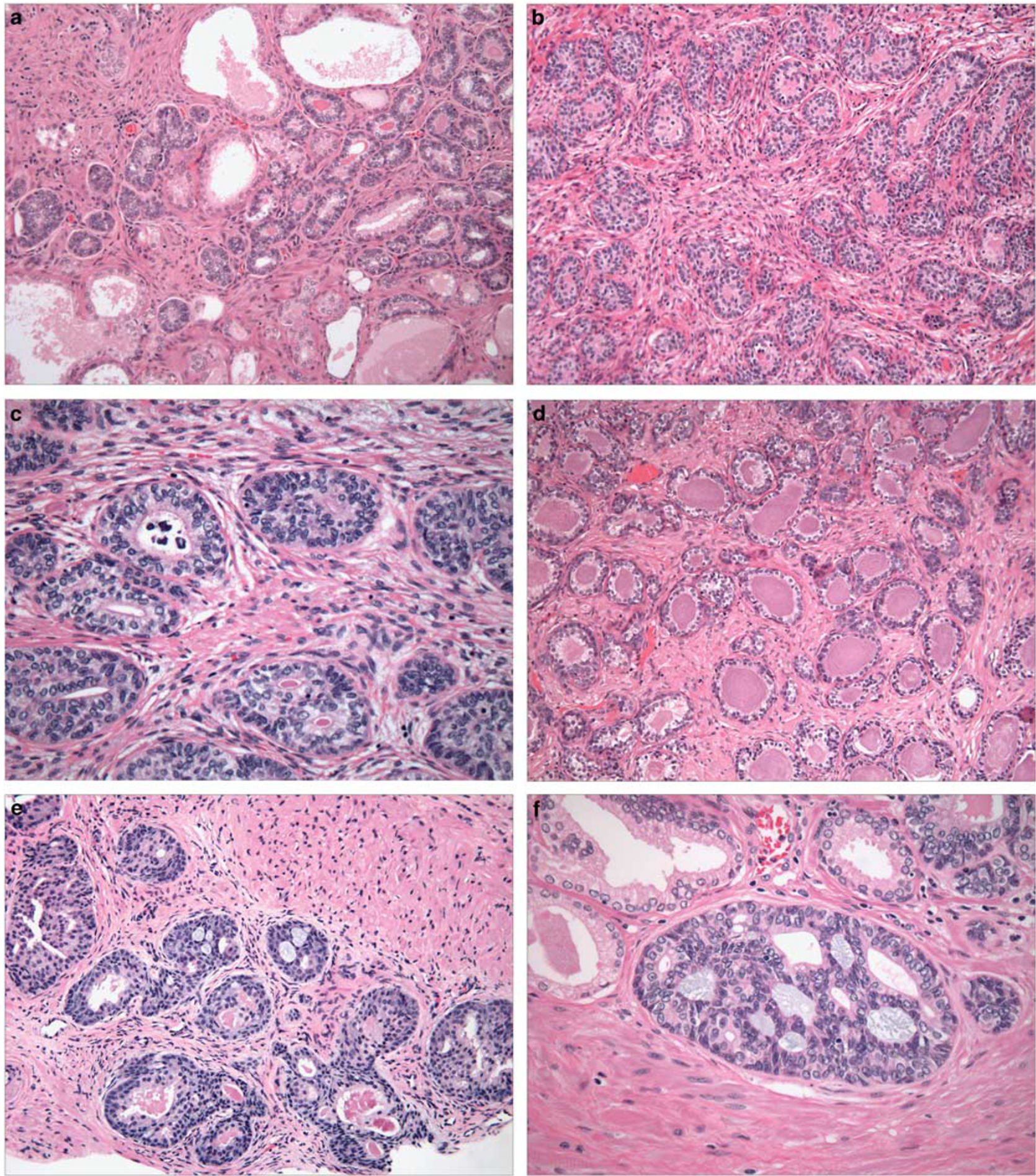

Figure 6 Basal cell hyperplasia. Basal cell hyperplasia can sometimes demonstrate an infiltrative growth, resembling Gleason pattern 3 adenocarcinoma (a). It may demonstrate busy architecture exhibiting complete (solid appearing) and incomplete patterns (b). The basal cells are dark with scant cytoplasm and have round to oval, or spindled, hyperchromatic nuclei. The proliferating basal cells may show irregular arrangement and usually appear 'piled up' with two or more cell layers present (c). Basal cell hyperplasia frequently contains microcalcifications in the glandular lumina (c) and intracytoplasmic eosinophilic globules (d). Infrequently basal cell hyperplasia may demonstrate cribriform or pseudocribriform morphology, resembling cribriform prostatic carcinoma (Gleason pattern 4). Luminal dense eosinophilic secretions and blue mucin may be present, features that may also raise a question of possible prostatic carcinoma (e,f).

glands exhibiting crowded cribriform and complex papillary proliferations, which mimic cribriform pattern 4 carcinoma. Similar cribriform and papillary morphology can also be seen in the central zone of the prostate gland, which is often sampled in the biopsy cores from the base. These two represent 

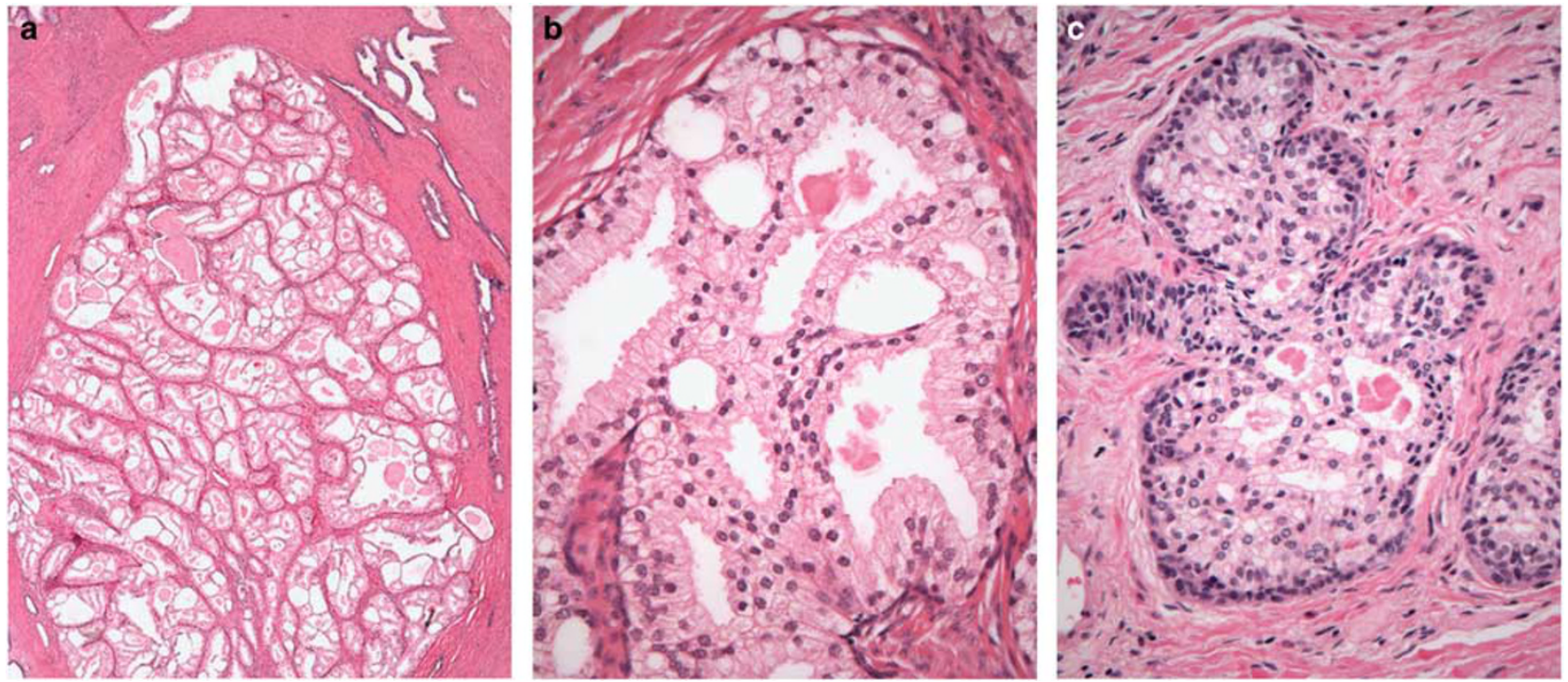

Figure 7 Clear cell cribriform hyperplasia. This lesion is formed by glands exhibiting crowded cribriform and complex papillary proliferations, which mimic cribriform pattern 4 carcinoma. This is a typical example that is nodular and well circumscribed, which can be appreciated at low magnification (a). Cribriform glands show clear or pale cytoplasm and uniform, round lumina and the nuclei are bland, uniform and without prominent nucleoli (b). The basal cells frequently form a recognizable layer at the periphery (c).

the prototypical examples of benign cribriforming lesions worth remembering.

At low power, this lesion typically demonstrates circumscribed and nodular appearance, but may also show a more diffuse growth (Figure $7 \mathrm{a}$ ). As the name implies, the cribriform glands of clear cell cribriform hyperplasia show clear or pale cytoplasm and uniform, round lumina (Figure 7b). The secretory cells are cuboidal to low-columnar and the nuclei are bland, uniform and without prominent nucleoli. The basal cells form a continuous and well-formed layer at the periphery (Figure 7c). The immunostains for HMWK can highlight the basal cell layer, although this is usually unnecessary. Cribriform hyperplasia is a completely benign lesion and it does not represent a risk factor for subsequent development of carcinoma.

Differential diagnosis. Clear cell cribriform hyperplasia can be confused with both high-grade PIN and with cribriform pattern 4 acinar adenocarcinoma. The distinction of cribriform hyperplasia from cribriform carcinoma and cribriform pattern highgrade PIN is based on the bland cytology of the cribriform hyperplasia with demonstrating absence of significant cytologic atypia and prominent nucleoli in the secretory cells and the presence of prominent and continuous basal cell layer.

\section{Nephrogenic Adenoma (Metaplasia)}

Nephrogenic adenoma (metaplasia) is a benign lesion that most commonly involves the urinary bladder, but it may also be encountered in the renal pelvis and the ureters. ${ }^{45-47}$ Nephrogenic adenoma (metaplasia) may also occur rarely in the prostatic urethra and may mimic prostatic carcinoma on TUR specimens. ${ }^{46}$ Nephrogenic metaplasia (adenoma) is usually a small and solitary, incidental lesion, but larger lesions have also been reported; it can also be a multifocal lesion. This lesion has been often associated with a previous local irritation or trauma due to surgical resections, instrumentation, stones, and in some cases it may occur after renal transplantation. Studies in renal transplant patients suggested that nephrogenic metaplasia (adenoma) is indeed of renal origin, resulting from implantation of the renal tubular cells along the urinary tract. ${ }^{48}$ Another theory of its pathogenesis (at least in some cases) includes a local metaplastic process, likely due to prior urothelial injury.

Main histologic patterns of this lesion include: tubular, cystic, polypoid-papillary, and flat (Figures 8a and b). The majority of cases consist of small round to oval tubules lined by single row of uniform, low columnar, or cuboidal epithelial cells, containing eosinophilic to rarely clear cytoplasm. Mitotic figures are usually absent. Occasional tubules or glands may also contain colloid-like eosinophilic secretions, mimicking thyroid follicles or mesonephric gland hyperplasia (Figure 8c). Some tubules are lined by hobnail cells with prominent nucleoli that may resemble signet-ring cells (Figure 8d). The small tubules may contain blue mucin, mimicking prostatic adenocarcinoma (Gleason pattern 3), or even signet-ring cell carcinoma (Gleason pattern 5). A helpful feature is the presence of a thickened hyaline rim, seen at least around some of the tubules, which may be highlighted with PAS. Some cases arising in the prostatic urethra may also 

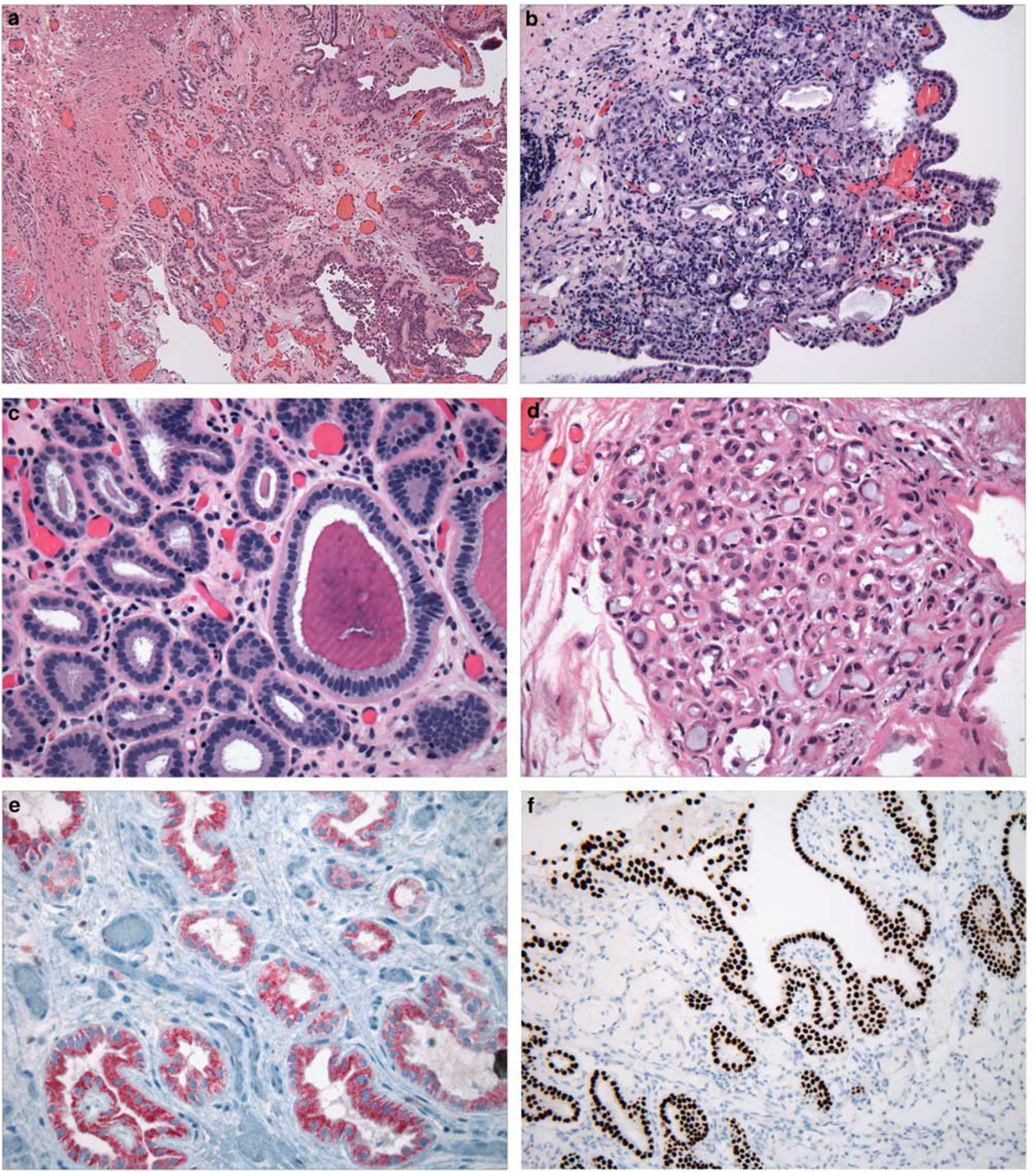

Figure 8 Nephrogenic adenoma (metaplasia). Nephrogenic adenoma (metaplasia) may show several morphologic patterns including tubular, polypoid-papillary, and flat (a-d). The lesion is typically noninfiltrative and may be set in an inflammatory background (b). The majority of cases show small round to oval tubules lined by a single row of uniform, low columnar, or cuboidal cells, containing eosinophilic to rarely clear cytoplasm. Some tubules may also contain colloid-like eosinophilic secretions, mimicking thyroid follicles (c). Some smaller tubules are lined by hobnail cells which may resemble signet-ring cells and also may contain blue mucin, mimicking prostatic adenocarcinoma (Gleason pattern 3) or even signet-ring cell carcinoma (Gleason pattern 5) (d). Thickened hyaline rim, seen at least around some of the tubules, may be a helpful feature. A frequent 'malignant immunoprofile' mimicking prostatic adenocarcinoma, may create confusion with uniform lack of staining for HMWK and reactivity for AMACR (e). This lesion typically shows PAX-8 reactivity (f). 

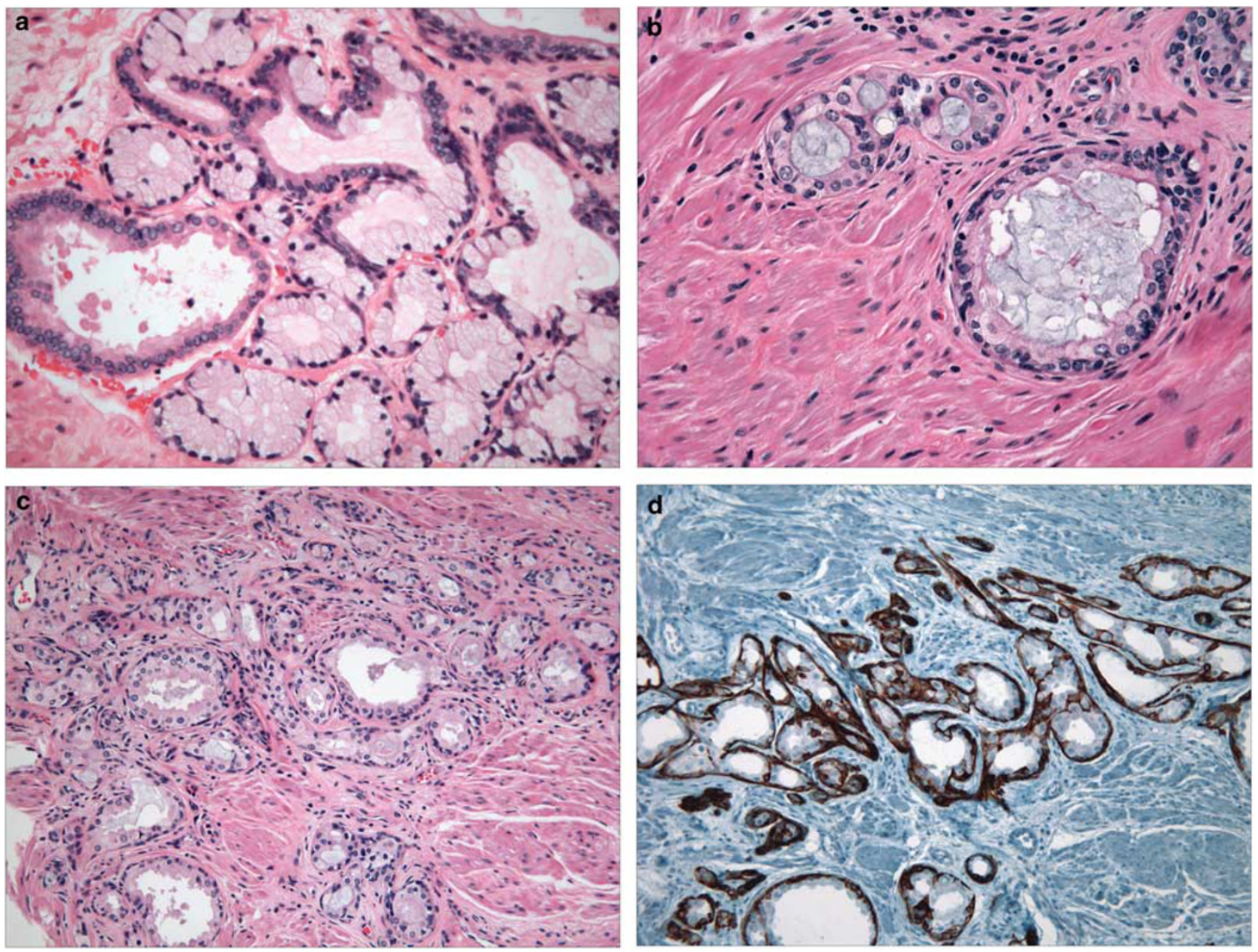

Figure 9 Mucinous metaplasia. Mucinous metaplasia represents a replacement of the normal prostatic epithelium with mucin containing goblet cells (a). This metaplastic change can rarely demonstrate morphology that mimics prostate adenocarcinoma, particularly with crowded architecture and luminal extravasation of mucin (b,c). The basal cells are uniformly positive for HMWK (Cytokeratin 5/6) (d).

show muscle involvement that can be worrisome, but are often found in continuity with the more typical patterns, located closer to the urothelium. Variable amount of edema and inflammation are almost always present, but desmoplasia is not seen. Features incompatible with a diagnosis of nephrogenic metaplasia (adenoma) include: solid growth, diffuse clear cell change, marked cytologic atypia, and brisk mitotic activity.

Nephrogenic metaplasia (adenoma) often shows a 'malignant immunoprofile' mimicking prostatic adenocarcinoma, which may create confusion: uniform absence of staining for HMWK and p63 and reactivity for AMACR, seen in more than half of the cases (Figure 8e). ${ }^{49,50}$ However, this lesion is typically reactive for PAX-2 and PAX-8 (Figure 8f), as well as Cytokeratin 7. Focal and weak reactivity for PSA and PSAP may also be seen.

Differential diagnosis. Nephrogenic metaplasia (adenoma) showing small glandular proliferation with prominent nucleoli, signet-ring morphology, luminal mucin and 'malignant immunoprofile' can mimic prostatic carcinoma in TUR specimens. However, the recognition of the full spectrum of the morphologic features of this lesion and the awareness of the typical immunoprofile should be sufficient to make this distinction.

\section{Mucinous Metaplasia}

Mucinous metaplasia represents a replacement of the normal prostatic epithelium with mucin containing goblet cells. This rare metaplastic change can rarely demonstrate morphology that mimics prostate adenocarcinoma. ${ }^{51,52}$ In mucinous metaplasia, the benign glands are lined by cells showing mucinfilled cytoplasm, usually displaying small, dark, basal nuclei (Figure 9a). Mucinous metaplasia may involve individual acinar cells, entire acini or even clusters of acini. Luminal extravasation of mucin can also be found in the benign glands that sometimes may be a reason for concern (Figures $9 \mathrm{~b}$ and c). The mucin containing cells stain positive for PAS, 
PAS-D, mucicarmine, and Alcian blue. The immunostains for PSA and PSAP are negative. The basal cells are uniformly positive for HMWK and p63 (Figure 9d).

Differential diagnosis. Florid mucinous metaplasia may mimic a foamy-type prostatic adenocarcinoma, which is however composed of larger glands demonstrating an infiltrative growth pattern, containing voluminous cells with microvesicular, foamy (or xanthomatous) cytoplasm, usually without a luminal mucin. ${ }^{53-56}$ Luminal eosinophilic secretions are often present and the basal cells are lacking in foamy-type carcinoma, in contrast to mucinous metaplasia, which can be easily confirmed with immunostains for HMWK and p63. Florid mucinous metaplasia can also be confused with benign Cowper's glands, which are however located outside the prostate, in the bulbourethral area.

\section{Mesonephric Remnant Hyperplasia}

Mesonephric remnants represent a rare and incidental histologic finding. Mesonephric ducts embryologically give rise to the ejaculatory ducts and primordial ureters and the remnants may persist in the bladder neck and the prostate base or around the seminal vesicles. When the mesonephric remnants are hyperplastic they may mimic prostatic adenocarcinoma Gleason pattern 3 on needle biopsy, TUR, or radical prostatectomy. ${ }^{57-59}$ They are preferentially found in the anterior fibromuscular stroma and in the adjacent anterolateral periprostatic tissue, and also in the posterior and posterolateral base or bladder neck area, either within or outside the prostate (Figures 10a and b).

This lesion is characterized by vaguely lobular or, less often, an infiltrative proliferation of small tubules or atrophic appearing glands, lined by a single layer of epithelium. The lining cells are bland, contain scant cytoplasm and usually show no atypia, nuclear enlargement or prominent nucleoli. The small, atrophic appearing acini typically contain dense, eosinophilic, colloid-like secretion. The second most common pattern consists of small acini with occasional micropapillary buds and empty lumina, reminiscent of nephrogenic metaplasia. On immunostains, mesonephric remnant hyperplasia typically shows diffuse reactivity for PAX-8. ${ }^{59}$ There is variable, mostly negative reactivity for HMWK and p63, and focal positivity for AMACR may be seen, an immunoprofile that may raise suspicion for prostatic carcinoma; PSA and PSAP are however negative. ${ }^{59}$

Differential diagnosis. Because of the focal infiltrative appearance and the extraprostatic location, mesonephric remnant hyperplasia occasionally needs to be distinguished from prostatic carcinoma. The features such as dense eosinophilic luminal content, atrophic cytoplasm, and papillary luminal
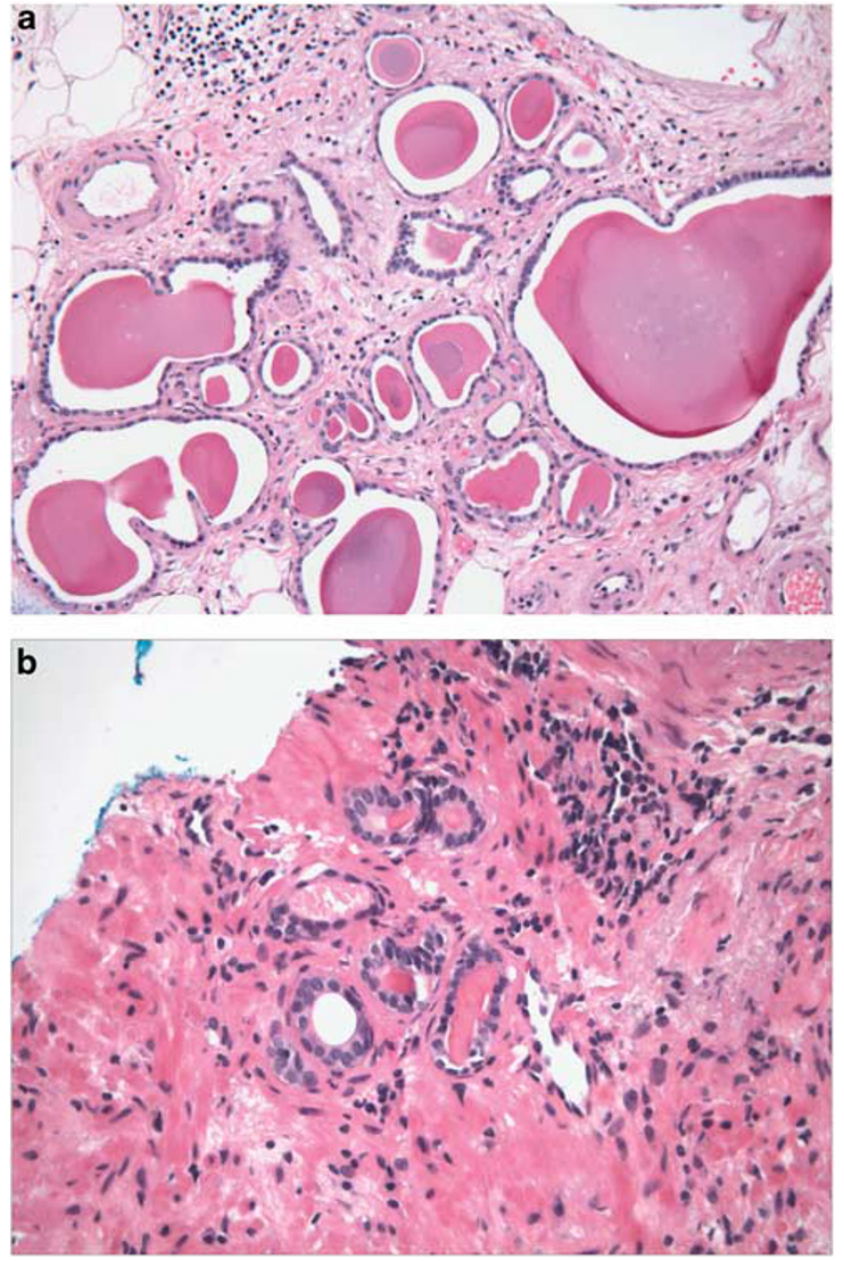

Figure 10 Mesonephric remnant hyperplasia. Mesonephric remnants represent a rare and incidental histologic finding, which may mimic prostatic adenocarcinoma Gleason pattern 3. They are preferentially found in the anterior fibromuscular stroma and in the adjacent anterolateral periprostatic tissue (a) on TUR or exceptionally rarely on needle biopsy (b). This lesion is characterized by vaguely proliferation of small tubules or atrophic appearing glands, lined by a single layer of epithelium, typically contain dense, eosinophilic, colloid-like secretions.

buddings (if present) are helpful in establishing the correct diagnosis. An immunophenotype with PAX-8 positivity may also be helpful. Some patterns of nephrogenic metaplasia (adenoma) may also resemble mesonephric remnant hyperplasia, but the nephrogenic metaplasia (adenoma) is typically a periurethral lesion, rather than periprostatic or at the prostate periphery.

\section{Verumontanum Mucosal Gland Hyperplasia}

Verumontanum mucosal gland hyperplasia is a benign, small acinar proliferation found in the area of the verumontanum, where the utricle and the ejaculatory ducts merge with the prostatic urethra. ${ }^{60,61}$ It is an exceptionally rare finding in prostatic biopsies and is almost never sampled in 

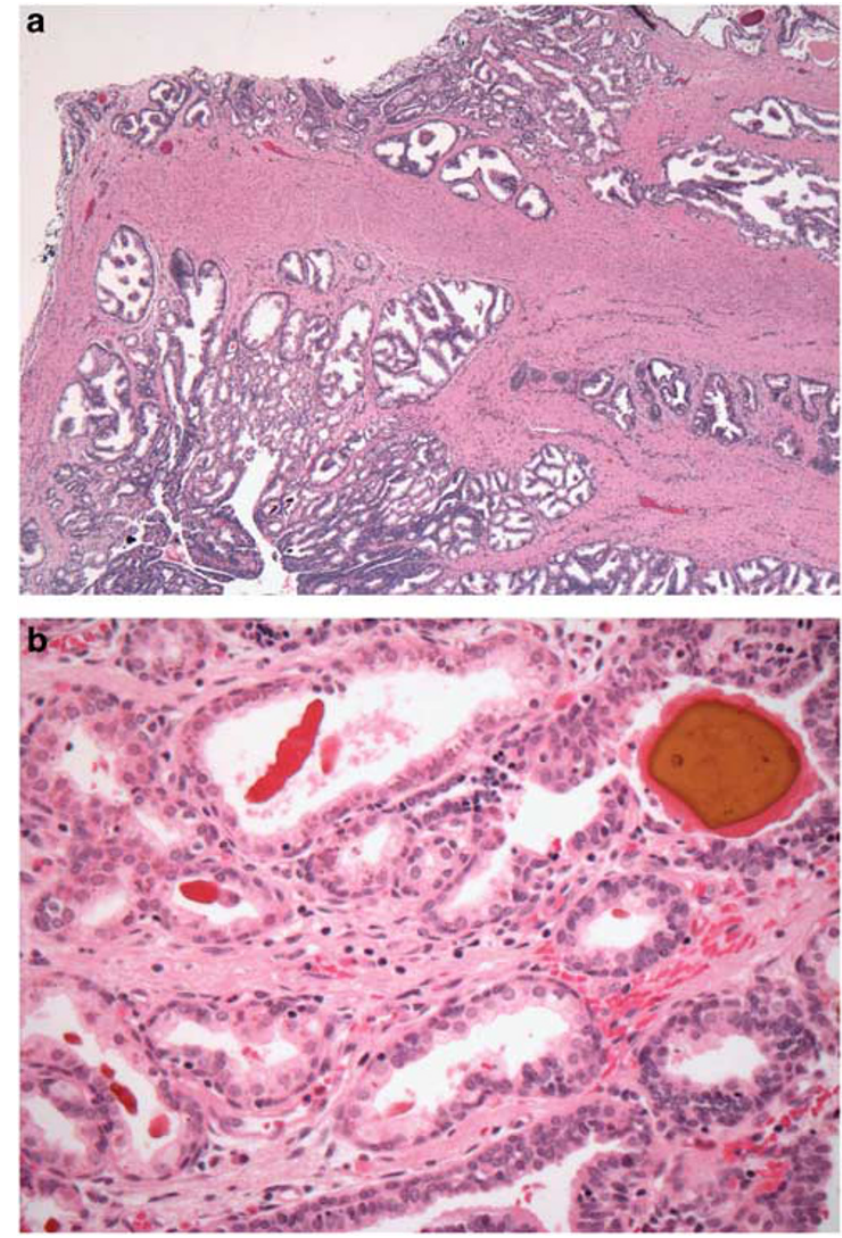

Figure 11 Verumontanum mucosal gland hyperplasia. Verumontanum mucosal gland hyperplasia is a benign, small acinar proliferation found in the area of the verumontanum (a). It is characterized by relatively uniform and circumscribed, closely packed, small acini, with intact basal cell layer. The finding of luminal brown-orange luminal secretions, which are frequent, is helpful for the diagnosis (b).

TUR specimens because verumontanum is spared in this procedure. Most often it is incidentally found in radical prostatectomies.

The lesion is characterized by relatively uniform and circumscribed, closely packed, small acini, with intact basal cell layer (Figure 11a). They show small, uniform, and bland nuclei with inconspicuous nucleoli. The finding of distinctive brown-orange luminal secretions, which are frequent, is helpful for the diagnosis (Figure 11b). Intraluminal corpora amylacea are also found. Verumontanum mucosal gland hyperplasia is identified often in continuity with the prostatic urethral urothelium. The glands of this lesion are similar to the prostatic acini by immunoprofile: secretory cells are reactive with PSA, whereas the basal cells react with antibodies to HMWK and p63.

Differential diagnosis. The main entity to exclude in the differential diagnosis is low-grade prostatic adenocarcinoma (Gleason pattern 3). Some of the glands of the verumontanum gland hyperplasia may show papillary infoldings introducing the differential of prostatic duct adenocarcinoma. However, the glands of verumontanum hyperplasia typically lack the infiltrative and haphazard arrangement of the neoplastic acini seen in adenocarcinoma and demonstrate bland cytologic features. The distinctive intraluminal rust-orange secretions and the presence of basal cell layer further distinguish this lesion from prostatic adenocarcinoma.

\section{Normal Tissues in Prostate Specimens Mimicking Prostatic Carcinoma}

Benign crowded prostatic glands, seminal vesicles and ejaculatory ducts, Cowper's glands, paraganglia, benign prostate glands around nerves, and rectal mucosa all represent normal anatomic structures that are usually readily recognized and easily separated from malignancy. However, all these benign structures may in some situations present a diagnostic problem, particularly in limited needle biopsy specimens.

\section{Benign Crowded Glands}

Gland architecture may appear unusually busy in some benign prostate specimens, demonstrating more prominent gland crowding, which may raise diagnostic consideration for prostatic adenocarcinoma, particularly with some less common carcinoma patterns mimicking benign morphology, ${ }^{1}$ such as pseudohyperplastic, ${ }^{62,63}$ foamy, ${ }^{53-56}$ or atrophic. ${ }^{23,24}$ In a limited biopsy specimen, the circumscribed and noninfiltrative nature of the benign glandular proliferations may be less obvious, but the lack of cytologic atypia and the uniform presence of basal cells, demonstrated on immunostains are usually sufficient to alleviate the diagnostic uncertainty (Figures 1a and b).

\section{Seminal Vesicles and Ejaculatory Ducts}

Seminal vesicles or ejaculatory ducts may be rarely sampled on prostate needle biopsy, unless they are specifically targeted (for example, for staging purposes in post-cryotherapy biopsies). However, due to the limited tissue in needle biopsies, it may be sometimes difficult to recognize the characteristic morphology of these structures. Cytologic atypia, which is typically seen in seminal vesicle epithelium, can also raise a suspicion for prostatic adenocarcinoma.

Seminal vesicles are characterized by central dilated lumina, surrounded by numerous small glands, clustered at the periphery, which appear to bud off from the central lumen (Figures 12a and b). Seminal vesicle tissue can sometimes be seen in core 

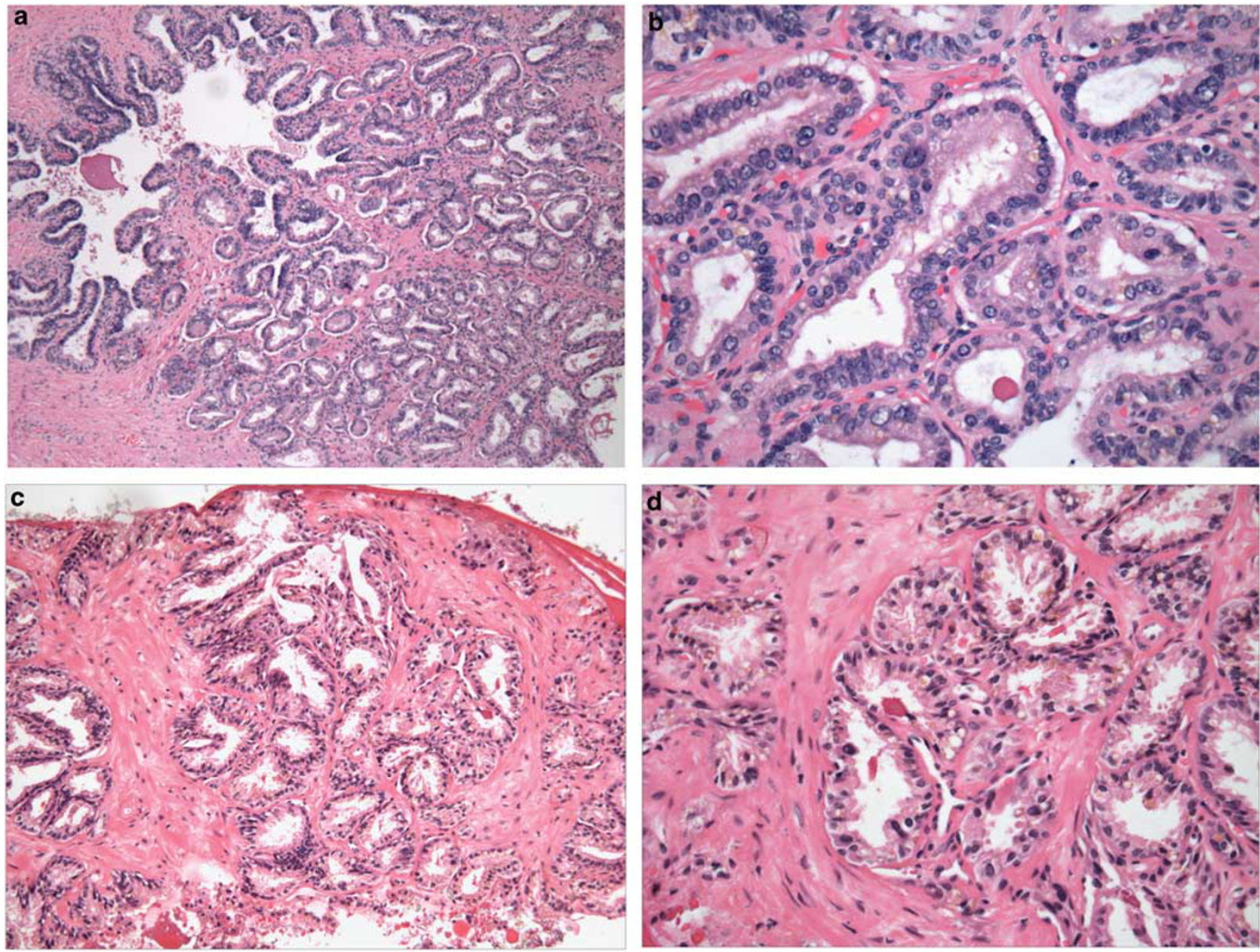

Figure 12 Seminal vesicle. Seminal vesicles are characterized by central dilated lumina, surrounded by numerous small glands, which appear to bud off from the central lumen (a). Seminal vesicle epithelium has two cell layers: columnar cells and basal cells. Columnar cells contain golden-brown lipofuscin pigment, which may sometimes be subtle. Prominent nuclear atypia, pleomorphism, marked nuclear hyperchromasia with smudged chromatin are often seen (b). Seminal vesicle tissue can sometimes be seen in core biopsies, often at the edge of the core (c). Typically, there are abundant lipofuscin, nuclear atypia, and luminal crystaloids that allow correct recognition (d).

biopsies, often at the edge of the core, where the tissue appears fragmented as the needle enters the seminal vesicle (Figures 12c and d). Seminal vesicle epithelium has two cell layers: columnar cells and basal cells. Columnar cells have short microvilli and characteristically contain large amount of goldenbrown lipofuscin pigment. Prominent nuclear atypia, pleomorphism, marked nuclear hyperchromasia with smudged chromatin are often seen. The nuclear atypia of the seminal vesicle is degenerative and resembles the nuclear changes seen with radiation. The nucleoli can be prominent and nuclear inclusions are frequently found. Eosinophilic secretions and crystalloids are also frequent luminal findings.

Seminal vesicles typically show a thick muscular layer surrounding the glands, which is progressively attenuated and disappears around the ejaculatory duct in its course within the prostate. Thus, although the ejaculatory duct epithelium appears similar and often indistinguishable on needle biopsy from that of the seminal vesicle epithelium, it typically lacks a well-formed muscular layer within the prostate, where it is surrounded only by fibroconnective tissue containing small vascular channels. The distinction between seminal vesicles and ejaculatory ducts, although difficult in limited specimens, is of practical importance, because the presence of prostatic carcinoma in ejaculatory duct tissue does not indicate extraprostatic extension, whereas seminal vesicle involvement represents a high-stage disease. On needle biopsy, if uncertainty persists regarding the correct identification of these structures, particularly if the tissue is limited, a sign-out may include a statement that 'normal seminal vesicle/ejaculatory duct type epithelium is present'.

The epithelium of the seminal vesicles and the ejaculatory ducts is typically negative for PSA and PSAP when monoclonal antibodies are used. The basal cells demonstrate uniform reactivity for HMWK and p63. There is also a nuclear expression of PAX-2 and PAX-8, markers of mesonephric derivation. ${ }^{64}$ 

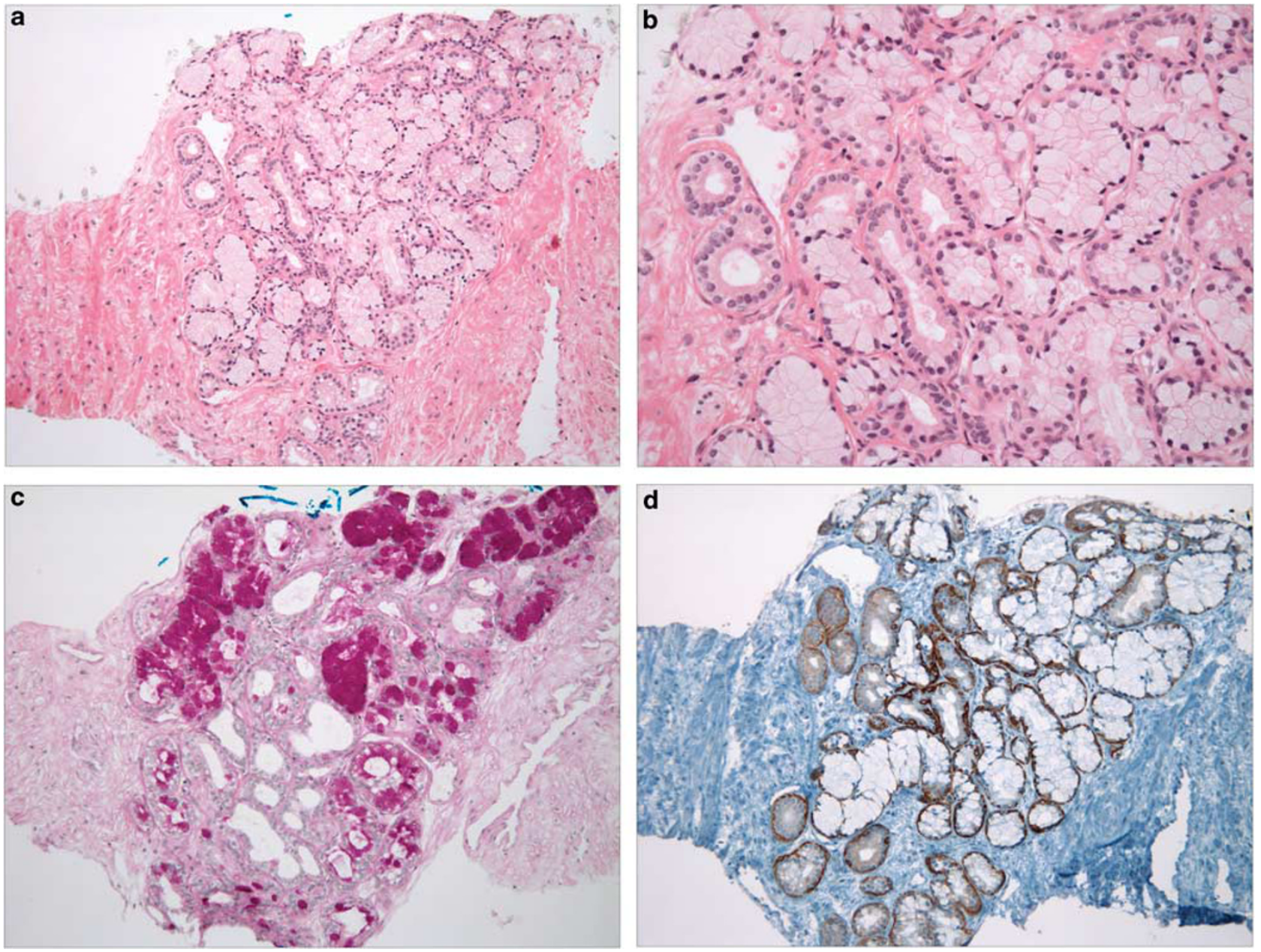

Figure 13 Cowper's glands. Cowper's glands can be rarely found in prostatic specimens obtained by TUR or needle biopsies, typically sampled from the prostatic apex (a). They are composed of compact and well-circumscribed lobules of small, tightly packed and uniform acini, arranged around several larger ducts (b). Cowper's glands are PAS-D positive (c) and HMWK marks the ductal epithelium, but is not as prominent in the attenuated peripheral basal cells in the acini (d).

MUC-6 marks the normal seminal vesicle/ejaculatory duct epithelium, but not the benign prostate glands or prostatic adenocarcinoma. ${ }^{65}$

Differential diagnosis. Although seminal vesicle tissue can be confused with prostate cancer in a limited biopsy specimens, one can rarely see as severe degree of nuclear atypia and marked pigment content in prostatic carcinoma as in the seminal vesicles. If a targeted sampling of the seminal vesicles has been undertaken for staging or in posttreatment biopsies, and the tissue has been submitted as 'seminal vesicle', pathologist has to provide a clear statement whether benign seminal vesicle (or prostatic) tissue has been identified, and whether prostatic carcinoma has been found in the sample.

\section{Cowper's Glands}

Cowper's glands, also known as bulbourethral glands, are paired pea-shaped glands, located outside the prostate in the urogenital diaphragm, lateral to the membranous urethra and near the prostatic apex. ${ }^{66}$ Cowper's glands can however be rarely found in prostatic specimens obtained by TUR or needle biopsies, typically sampled from the prostatic apex. They are composed of wellcircumscribed lobules of small, tightly packed and uniform acini, arranged around several larger ducts (Figure 13a). The acini comprises mucin-containing cells with small basal nuclei, inconspicuous nucleoli and markedly attenuated basal cell layer (Figure 13b). The glands may also be surrounded by skeletal muscle. The compact glandular arrangement and the bland cytology with small nuclei and inconspicuous nucleoli represent the typical Cowper's glands features.

Cowper's glands are mucicarmine, PAS-D (Figure 13c) and Alcian blue positive. HMWK marks strongly the ductal epithelium, but is not as prominent in the attenuated peripheral basal cells in the acini (Figure 13d). Smooth muscle actin reactivity has also been reported in the basal cells. 

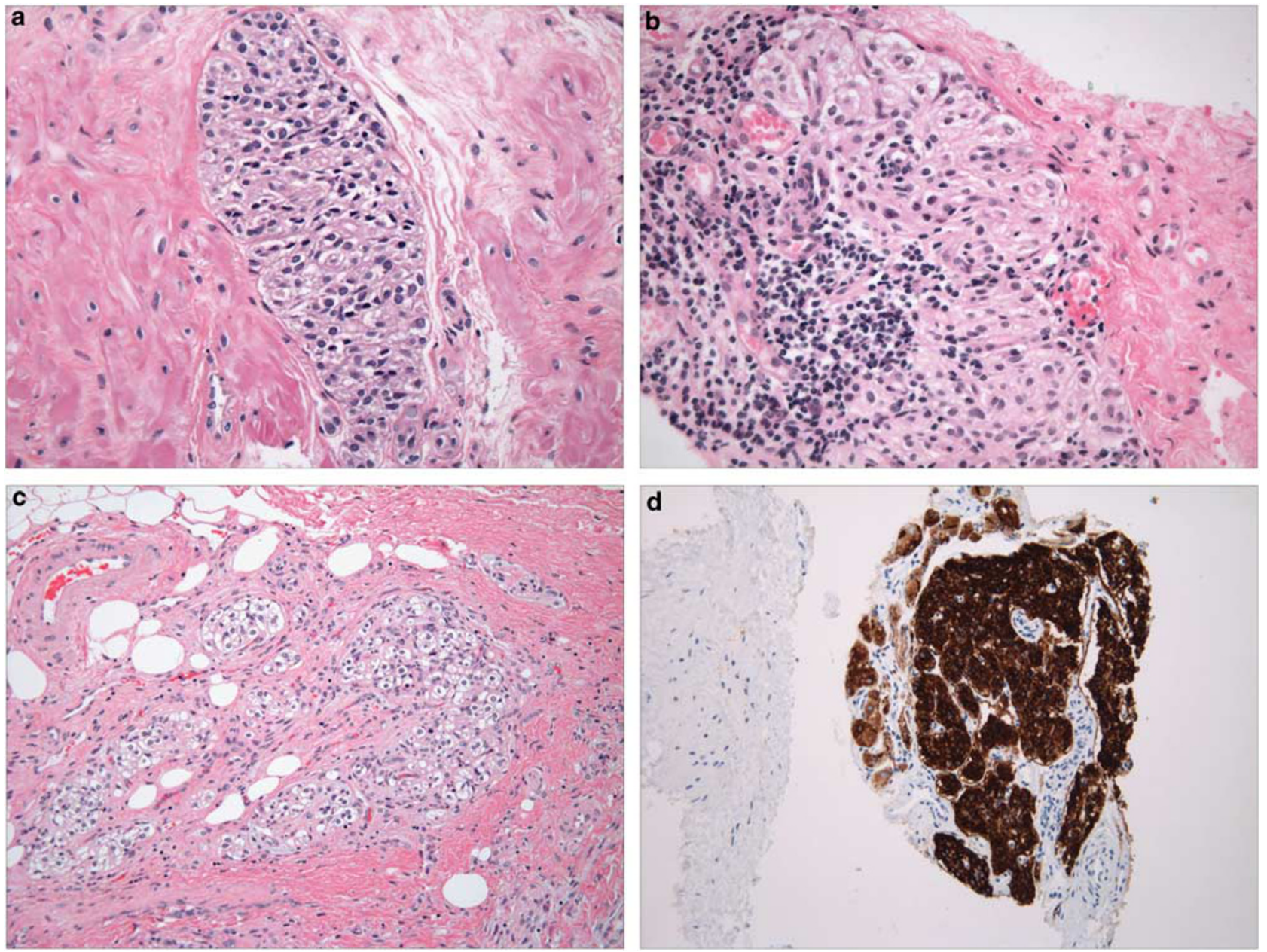

Figure 14 Paraganglion. Paraganglia represent small, solid collections of cells with clear or more commonly amphophilic, granular cytoplasm that can rarely be seen in needle biopsy specimens (a). Prominent vascularity can often be recognized at the periphery of the lesion (b). Misinterpretation of the extraprostatic paraganglia in radical prostatectomy specimens as prostatic adenocarcinoma may also lead to overstaging (c). They are positive for neuroendocrine markers, such as chromogranin (d).

PSA and PSAP are negative, although weak and focal PSA reactivity may be present in the acinar cells.

Differential diagnosis. Cowper's glands may resemble foamy gland carcinoma (typically Gleason pattern 3). ${ }^{67,68}$ Cowper's glands can be distinguished from carcinoma by their compact and non-infiltrative architecture, bland cytologic features, and abundant mucin-filled cytoplasm. Although foamy gland carcinomas may also demonstrate abundant cytoplasm, the neoplastic glands are typically larger, more irregular and the cytoplasm demonstrates foamy texture. They also show infiltrative growth and the mucin stains are negative. ${ }^{53-56}$ The immunostains in foamy carcinoma show PSA and PSAP reactivity and absence of HMWK and p63; mucicarmine is also negative. Florid mucinous metaplasia, another benign lesion, is typically found within the prostate and usually involves glands admixed within normal prostatic glands, rather than absence of normal prostate glands or presence of skeletal muscle, as typically seen in Cowper's glands.

\section{Paraganglion}

Paraganglia are collections of neuroendocrine cells that are usually located outside the prostate, in or adjacent to the lateral neurovascular bundles. They can also be identified occasionally within the prostatic stroma or in the bladder neck smooth muscle. Paraganglia may be rarely seen in TUR or needle biopsy specimens, where they can be misdiagnosed as high-grade prostatic carcinoma (Figures 14a and b). ${ }^{69-71}$ Misinterpretation of the extraprostatic paraganglia in radical prostatectomy specimens as prostatic adenocarcinoma may also lead to overstaging (Figure 14c). ${ }^{72}$

Paraganglia represent small, solid collections of cells with clear or more commonly amphophilic, granular cytoplasm, often displaying nested (zellballen) arrangement. The nuclei are small and often hyperchromatic, and the nucleoli are inconspicuous. Glandular differentiation is typically absent. A prominent vascularity, which can be more easily recognized toward the periphery of the lesion is a helpful finding. The cells are positive for 

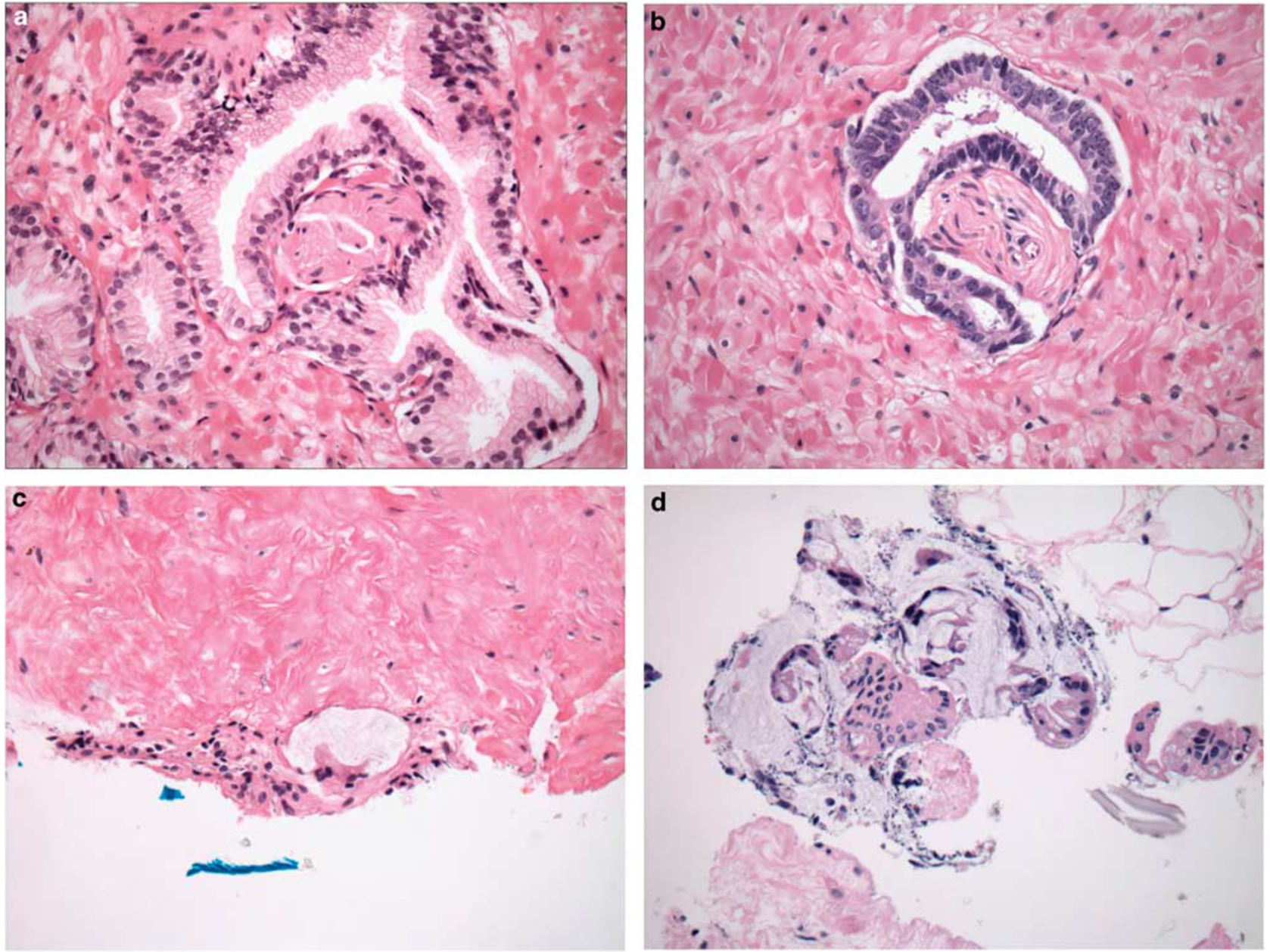

Figure 15 Benign prostatic glands mimicking perineural invasion and distorted rectal tissue mimicking prostatic carcinoma. Benign prostatic glands can occasionally completely wrap around a nerve, mimicking perineural invasion (a). Perineural involvement by benign glands must be distinguished from true perineural invasion by carcinoma, which is a pathognomonic finding for carcinoma (b). Rectal tissue is frequently found distorted in needle core biopsies and it may mimic prostatic carcinoma, particularly due to the presence of luminal mucin. A single rectal gland with luminal mucin, compressed along the core edge, mimicking prostatic adenocarcinoma (c). Fragmented rectal mucosa admixed with mucin, adjacent to the core tissue, may raise suspicion for prostatic carcinoma (d).

neuroendocrine markers, such as chromogranin (Figure 14d), synaptophysin, and neuron-specific enolase; negative stains include PSAP, PSA, AMACR, and HMWK.

Differential diagnosis. Although paraganglia may mimic high-grade prostatic carcinoma (Gleason pattern 5), the presence of bland morphology, the characteristic granular and amphophilic cytoplasm, and the vascular component are helpful clues in establishing the correct diagnosis. If they are not recognized or at least thought of on morphology and immunostains are ordered, a negative HMWK may also contribute to the diagnostic confusion.

\section{Benign Prostatic Glands in Perineural Spaces}

Benign prostatic glands can be found occasionally around or in close proximity to the nerves and can even be found, in extremely rare cases, within the nerves (Figure 15a). ${ }^{73-77}$ Several deceptive patterns can be seen: indentation, tracking, almost complete or incomplete wrapping, and intraneural benign glands. ${ }^{77}$ Perineural involvement by benign glands must be distinguished from true perineural invasion by carcinoma, which is a pathognomonic finding for prostatic adenocarcinoma (Figure 15b). The appreciation of the bland cytology and the benign gland architecture, which resembles the benign glands are helpful clues in recognizing this pitfall.

\section{Distorted Rectal Tissue Admixed with Prostate}

Rectal tissue is frequently found in needle core biopsies. However, when rectal tissue is distorted in the biopsy specimens, it may mimic prostatic carcinoma, particularly due to the presence of the fragmentation, luminal mucin, increased mitotic 

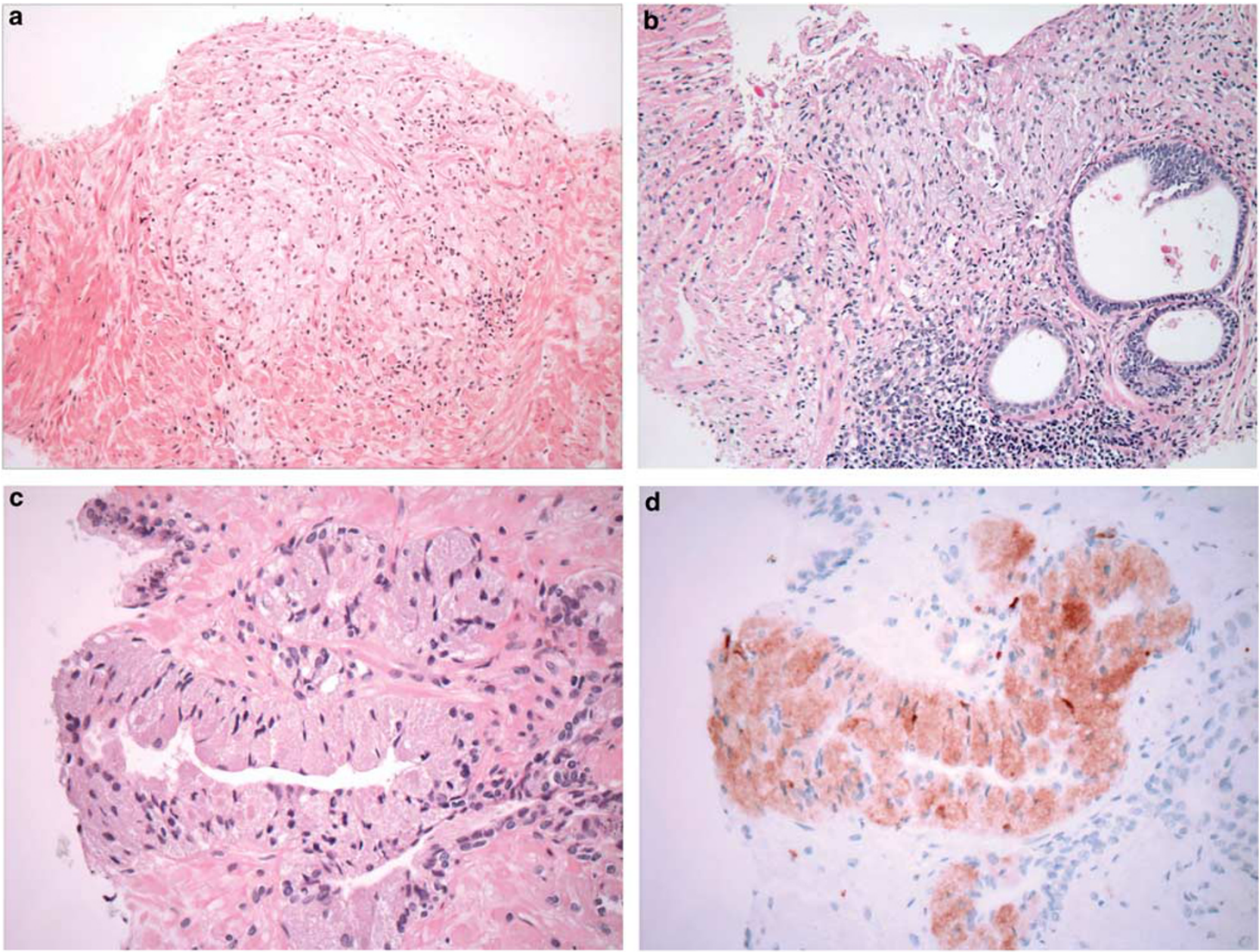

Figure 16 Xanthoma. Xanthoma is an incidental, rare finding on needle biopsy or less often in TUR specimens, forming circumscribed cell clusters (a), or rarely more irregular cord-like and individual cell growth, admixed with the normal glands (b). The cells have a clear to foamy, vacuolated cytoplasm and bland nuclei with inconspicuous nucleoli. Prostatic xanthoma may resemble foamy gland carcinoma (Gleason pattern 4), particularly on needle biopsy. Unusual xanthomatous change involving a prostatic gland (c); xanthomatous cells are however reactive for CD68 (d).

activity, and prominent nucleoli (Figures 15c and d). ${ }^{78}$ This issue may also be complicated by the misleading immunoprofile, demonstrating negative stains for HMWK and p63, and often positive AMACR. Helpful diagnostic clues include the recognition of the detached nature of the rectal fragments, isolated goblet cells, rectal lamina propria or muscularis propria (if present), and the negative PSA.

\section{Xanthoma}

Xanthoma is a localized collection of cholesterolladen histiocytes. Xanthoma is an incidental and rare finding on needle biopsy or less often in TUR specimens. ${ }^{79,80}$ Xanthoma usually forms small and circumscribed cell clusters, or rarely it may show infiltrative, cord-like and individual cell growth (Figures 16a-c). The cells have a clear to foamy, vacuolated cytoplasm, and bland nuclei with inconspicuous nucleoli. Prostatic xanthoma may resemble prostatic carcinoma, such as foamy gland carcinoma
(Gleason pattern 4), particularly on needle biopsy. ${ }^{53-56}$ When pseudoinfiltrative cord-like and individual cell patterns are present, they may mimic high-grade (Gleason pattern 5) carcinoma or hormone-treated carcinoma. Negative stains for HMWK may also create confusion. Xanthoma cells are reactive for CD68 (Figure 16d), a histiocytic marker, and they are negative for cytokeratins, PSA, PSAP, and AMACR.

Helpful features that aid in the recognition of xanthoma include the noninfiltrative character of the lesion and bland cytologic, and nuclear features. Immunohistochemistry may assist in the differential diagnosis, particularly in more problematic cases showing infiltrative pattern.

\section{Nonspecific Granulomatous Prostatitis}

Nonspecific granulomatous prostatitis is the most common form of granulomatous prostatitis, which can mimic prostatic adenocarcinoma clinically, due 

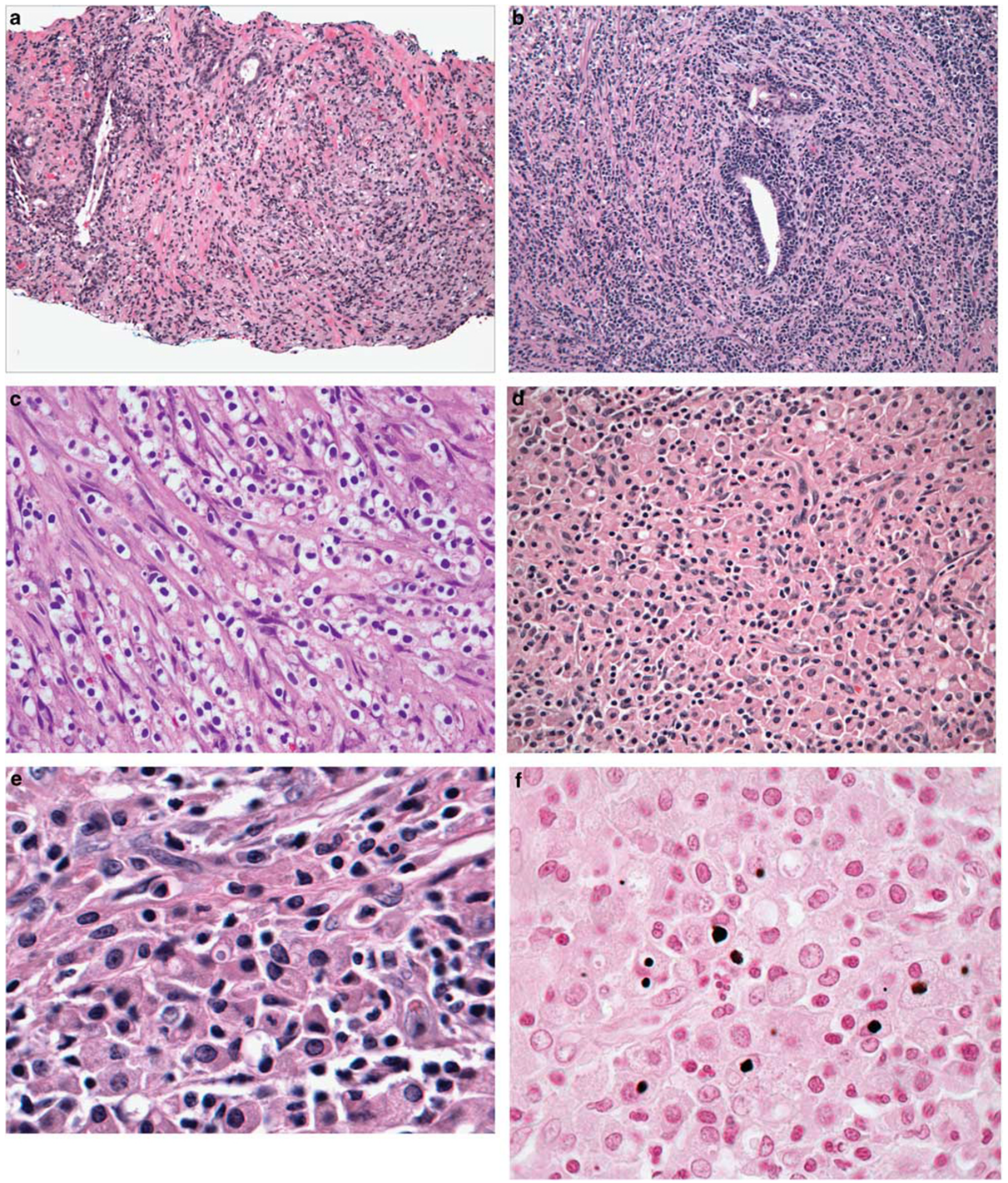

Figure 17 Nonspecific granulomatous prostatitis, malakoplakia and signet-ring lymphocytes. Nonspecific granulomatous prostatitis, composed of admixture of lymphocytes and epithelioid histiocytes can mimic prostatic carcinoma, particularly in limited biopsy tissue (a). On histology, it may mimic high-grade prostatic carcinoma (Gleason pattern 5) or small cell carcinoma, as shown (b). Thermal artifacts may result in signet ring-shaped lymphocytes that mimic signet-ring carcinoma (Gleason pattern 5) (c). Malakoplakia is a poorly circumscribed lesion characterized by diffuse sheets of macrophages, mostly representing epithelioid histiocytes with granular eosinophilic cytoplasm (von Hansemann histiocytes), admixed with lymphocytes, plasma cells, and neutrophils (d,e).They contain intracytoplasmic, spherical, sharply demarcated, and often concentrically laminated, basophilic inclusions, known as MichaelisGutmann bodies (e, center). They are typically positive for von Kossa stain (f). 
to abnormal rectal examination resulting from the hard, and fixed, nodular gland and elevated PSA. On histology, it may also mimic high-grade prostatic carcinoma (Gleason pattern 5 or small cell carcinoma), particularly in cases with prominent epithelioid (or foamy) histiocytes, often admixed with ruptured and inflamed ducts and acini, particularly in limited needle biopsy tissue (Figures 17a and b). ${ }^{81,82}$ The presence of extensive crush artifact may also exacerbate the diagnostic problem. Nonspecific granulomatous prostatitis represents a noncaseating granulomatous inflammatory reaction of foreignbody type to the extravasated prostatic fluid containing bacterial toxins and cell debris, due to acinar and duct blockage and rupture. It is also helpful to appreciate that this process is localized and ductcentric. Another important clue in avoiding a misdiagnosis of carcinoma is the recognition of the mixed inflammatory infiltrate, composed of epithelioid and foamy histocytes, lymphocytes, neutrophils and eosinophils. Although presence of multinucleated giant cells may also aid in the diagnosis, they are rarely found in nonspecific granulomatous prostatitis, but are often seen in infectious granulomas. Immunohistochemical stains for histiocytic and epithelial markers can reliably differentiate between the two entities. Epithelioid histiocytes are negative for pancytokeratin (AE1/ AE3), PSA, and PSAP and are positive for histiocytic markers, such as CD68. In cases with extensive crush artifact, the absence of HMWK staining in the inflammatory component may also be a pitfall.

\section{Signet-Ring Lymphocytes}

Thermally induced artifacts resulting in signetring-shaped lymphocytes and stromal cells may be occasionally seen in TUR specimens and may mimic signet-ring (Gleason pattern 5) carcinoma (Figure 17C). ${ }^{83,84}$

\section{Malakoplakia}

Malakoplakia ('soft plaque' in Greek) occurs rarely in the prostate, but it is more commonly found in the urinary bladder. In about half of the cases, the differential diagnosis includes malignancy, mainly because of the presence of a hard nodule on digital rectal examination and the hypoechoic areas seen on transrectal ultrasound imaging. ${ }^{85-89}$ Malakoplakia is a poorly circumscribed lesion characterized by diffuse sheets of macrophages, mostly representing epithelioid histiocytes with granular eosinophilic cytoplasm (von Hansemann histiocytes), admixed with lymphocytes, plasma cells, and neutrophils (Figures $17 \mathrm{~d}$ and e). They contain intracytoplasmic, spherical, sharply demarcated, and often concentrically laminated, basophilic inclusions, known as Michaelis-Gutmann bodies, which represent calcified bacterial debris (Figure 17e). They are typically positive for periodic acid-Schiff after diastase digestion (PAS-D) and von Kossa stain (for calcium) (Figure 17f), and are weakly positive (to negative) with Perls' Prussian blue stain (for iron). The absence of reactivity for cytokeratins, PSA, and PSAP, combined with positive staining for CD68, may aid in establishing the correct diagnosis. Malakoplakia may mimic poorly differentiated prostatic carcinoma (Gleason pattern 5) clinically, ultrasonographically, and histologically, particularly in limited biopsy specimens. Rare cases have been described in which malakoplakia and prostatic carcinoma have been simultaneously found in the prostate. ${ }^{85-89}$ The finding of Michaelis-Gutmann bodies essentially excludes a diagnosis of high-grade prostatic carcinoma.

\section{Conclusion}

It is important to be familiar with the characteristic features of the various benign mimics of prostatic adenocarcinoma to prevent an overdiagnosis and false-positive interpretation of the benign lesions as carcinoma. Although the accurate diagnosis of the benign mimics depends on the morphologic skills and the experience of the pathologists, it is also important to ensure proper technical handling and processing of the biopsies and other prostatic specimens for their optimal evaluation. A systematic, pattern-based approach can also help distinguish the mimics from prostatic adenocarcinoma Gleason patterns 3-5. Judicial use of immunostains and the awareness of the immunopatterns may also aid in establishing a correct diagnosis and ruling out prostatic adenocarcinoma.

\section{Disclosure/conflict of interest}

The author declares no conflict of interest.

\section{References}

1 Herawi M, Parwani AV, Irie J, et al. Small glandular proliferations on needle biopsies: most common benign mimickers of prostatic adenocarcinoma sent in for expert second opinion. Am J Surg Pathol 2005;29: 874-880.

2 Epstein JI, Egevad L, Amin MB, et al. The 2014 International Society of Urological Pathology (ISUP) Consensus Conference on Gleason Grading of Prostatic Carcinoma: Definition of Grading Patterns and Proposal for a New Grading System. Am J Surg Pathol 2016;40: 244-252.

3 Epstein JI, Allsbrook WC Jr, Amin MB, et al. The 2005 International Society of Urological Pathology (ISUP) Consensus Conference on Gleason Grading of Prostatic Carcinoma. Am J Surg Pathol 2005;29:1228-1242.

4 Srigley JR. Benign mimickers of prostatic adenocarcinoma. Mod Pathol. 2004;17:328-348. 
5 Netto GJ, Epstein JI. Benign mimickers of prostate adenocarcinoma on needle biopsy and TUR. Surg Pathol Clin 2008;1:1-41.

6 Hameed O, Humphrey PA. Pseudoneoplastic mimics of prostate and bladder carcinomas. Arch Pathol Lab Med 2010;134:427-443.

7 Harik LR, O'Toole KM. Nonneoplastic lesions of the prostate and bladder. Arch Pathol Lab Med 2012;136: 721-734.

8 Algaba F, Trias I. Mimickers of prostate cancer in needle biopsies. Anal Quant Cytopathol Histpathol 2015;37:57-64.

9 Gardner WA Jr, Culberson DE. Atrophy and proliferation in the young adult prostate. J Urol 1987;137: 53-56.

10 De Marzo AM, Platz EA, Epstein JI, et al. A working group classification of focal prostate atrophy lesions. Am J Surg Pathol 2006;30:1281-1291.

11 Franks LM. Atrophy and hyperplasia in the prostate proper. J Pathol Bacteriol 1954;68:617-621.

12 Billis A. Prostatic atrophy: an autopsy study of a histologic mimic of adenocarcinoma. Mod Pathol 1998;11:47-54.

13 Ruska KM, Sauvageot J, Epstein JI. Histology and cellular kinetics of prostatic atrophy. Am J Surg Pathol 1998;22:1073-1077.

14 Postma R, Schroder FH, van der Kwast TH. Atrophy in prostate needle biopsy cores and its relationship to prostate cancer incidence in screened men. Urology 2005;65:745-749.

15 Billis A. Prostatic atrophy. Clinicopathological significance. Int Braz J Urol 2010;36:401-409.

16 Cheville JC, Bostwick DG. Postatrophic hyperplasia of the prostate. A histologic mimic of prostatic adenocarcinoma. Am J Surg Pathol 1995;19:1068-1076.

17 Amin MB, Tamboli P, Varma M, et al. Postatrophic hyperplasia of the prostate gland: a detailed analysis of its morphology in needle biopsy specimens. Am J Surg Pathol 1999;23:925-931.

18 Przybycin CG, Kunju LP, Wu AJ, et al. Partial atrophy in prostate needle biopsies: a detailed analysis of its morphology, immunophenotype, and cellular kinetics. Am J Surg Pathol 2008;32:58-64.

19 Wang W, Sun X, Epstein JI. Partial atrophy on prostate needle biopsy cores: a morphologic and immunohistochemical study. Am J Surg Pathol 2008;32: 851-857.

20 Oppenheimer JR, Wills ML, Epstein JI. Partial atrophy in prostate needle cores: another diagnostic pitfall for the surgical pathologist. Am J Surg Pathol 1998;22: $440-445$.

21 Trpkov K, Bartczak-McKay J, Yilmaz A. Usefulness of cytokeratin 5/6 and AMACR applied as double sequential immunostains for diagnostic assessment of problematic prostate specimens. Am J Clin Pathol 2009;132: 211-220.

22 Farinola MA, Epstein JI. Utility of immunohistochemistry for alpha-methylacyl-CoA racemase in distinguishing atrophic prostate cancer from benign atrophy. Hum Pathol 2004;35:1272-1278.

23 Cina SJ, Epstein JI. Adenocarcinoma of the prostate with atrophic features. Am J Surg Pathol 1997;21: 289-295.

24 Egan AJ, Lopez-Beltran A, Bostwick DG. Prostatic adenocarcinoma with atrophic features: malignancy mimicking a benign process. Am J Surg Pathol 1997;21: 931-935.
25 Garcia JJ, Al-Ahmadie HA, Gopalan A, et al. Do prostatic transition zone tumors have a distinct morphology? Am J Surg Pathol 2008;32:1709-1714.

26 Bostwick DG, Srigley J, Grignon D, et al. Atypical adenomatous hyperplasia of the prostate: morphologic criteria for its distinction from well-differentiated carcinoma. Hum Pathol 1993;24:819-832.

27 Gaudin PB, Epstein JI. Adenosis of the prostate. Histologic features in TUR specimens. Am J Surg Pathol 1994;18:863-870.

28 Gaudin PB, Epstein JI. Adenosis of the prostate. Histologic features in needle biopsy specimens. Am J Surg Pathol 1995;19:737-747.

29 Grignon DJ, Sakr WA. Atypical adenomatous hyperplasia of the prostate: a critical review. Eur Urol 1996;30:206-211.

30 Green WM, Hicks JL, De Marzo A, et al. Immunohistochemical evaluation of TMPRSS2-ERG gene fusion in adenosis of the prostate. Hum Pathol 2013;44:1895-1901.

31 Lotan TL, Epstein JI. Diffuse adenosis of the peripheral zone in prostate needle biopsy and prostatectomy specimens. Am J Surg Pathol 2008;32:1360-1366.

32 Kramer CE, Epstein JI. Nucleoli in low-grade prostate adenocarcinoma and adenosis. Hum Pathol 1993;24: 618-623.

33 Yang XJ, Wu CL, Woda BA, et al. Expression of alphaMethylacyl-CoA racemase (P504S) in atypical adenomatous hyperplasia of the prostate. Am J Surg Pathol 2002;26:921-925.

34 Sakamoto N, Tsuneyoshi M, Enjoji M. Sclerosing adenosis of the prostate. Histopathologic and immunohistochemical analysis. Am J Surg Pathol 1991;15: 660-667.

35 Jones EC, Clement PB, Young RH. Sclerosing adenosis of the prostate gland. A clinicopathological and immunohistochemical study of 11 cases. Am J Surg Pathol 1991;15:1171-1180.

36 Grignon DJ, Ro JY, Srigley JR, et al. Sclerosing adenosis of the prostate gland. A lesion showing myoepithelial differentiation. Am J Surg Pathol 1992;16:383-391.

37 Luque RJ, Lopez-Beltran A, Perez-Seoane C, et al. Sclerosing adenosis of the prostate. Histologic features in needle biopsy specimens. Arch Pathol Lab Med 2003;127:e14-e16.

38 Cheng L, Bostwick DG. Atypical sclerosing adenosis of the prostate: a rare mimic of adenocarcinoma. Histopathology 2010;56:627-631.

39 Rioux-Leclercq NC, Epstein JI. Unusual morphologic patterns of basal cell hyperplasia of the prostate. Am J Surg Pathol 2002;26:237-243.

40 Yang XJ, Tretiakova MS, Sengupta E, et al. Florid basal cell hyperplasia of the prostate: a histological, ultrastructural, and immunohistochemical analysis. Hum Pathol 2003;34:462-470.

41 Thorson P, Swanson PE, Vollmer RT, et al. Basal cell hyperplasia in the peripheral zone of the prostate. Mod Pathol 2003;16:598-606.

42 Hosler GA, Epstein JI. Basal cell hyperplasia: an unusual diagnostic dilemma on prostate needle biopsies. Hum Pathol 2005;36:480-485.

43 Ayala AG, Srigley JR, Ro JY, et al. Clear cell cribriform hyperplasia of prostate. Report of 10 cases. Am J Surg Pathol 1986;10:665-671.

44 Frauenhoffer EE, Ro JY, el-Naggar AK, et al. Clear cell cribriform hyperplasia of the prostate. Immunohistochemical and DNA flow cytometric study. Am J Clin Pathol 1991;95:446-453. 
45 Oliva E, Young RH. Nephrogenic adenoma of the urinary tract: a review of the microscopic appearance of 80 cases with emphasis on unusual features. Mod Pathol 1995;8:722-730.

46 Allan CH, Epstein JI. Nephrogenic adenoma of the prostatic urethra: a mimicker of prostate adenocarcinoma. Am J Surg Pathol 2001;25:802-808.

47 Kunju LP. Nephrogenic adenoma: report of a case and review of morphologic mimics. Arch Pathol Lab Med 2010;134:1455-1459.

48 Mazal PR, Schaufler R, Altenhuber-Muller R, et al. Derivation of nephrogenic adenomas from renal tubular cells in kidney-transplant recipients. N Engl J Med 2002;347:653-659.

49 Gupta A, Wang HL, Policarpio-Nicolas ML, et al. Expression of alpha-methylacyl-coenzyme A racemase in nephrogenic adenoma. Am J Surg Pathol 2004;28: 1224-1229.

50 Skinnider BF, Oliva E, Young RH, et al. Expression of alpha-methylacyl-CoA racemase (P504S) in nephrogenic adenoma: a significant immunohistochemical pitfall compounding the differential diagnosis with prostatic adenocarcinoma. Am J Surg Pathol 2004;28:701-705.

51 Grignon DJ, O'Malley FP. Mucinous metaplasia in the prostate gland. Am J Surg Pathol 1993;17:287-290.

52 Bohman KD, Osunkoya AO. Mucin-producing tumors and tumor-like lesions involving the prostate: a comprehensive review. Adv Anat Pathol 2012;19: 374-387.

53 Nelson RS, Epstein JI. Prostatic carcinoma with abundant xanthomatous cytoplasm. Foamy gland carcinoma. Am J Surg Pathol 1996;20:419-426.

54 Tran TT, Sengupta E, Yang XJ. Prostatic foamy gland carcinoma with aggressive behavior: clinicopathologic, immunohistochemical, and ultrastructural analysis. Am J Surg Pathol 2001;25:618-623.

55 Hudson J, Cao D, Vollmer R, et al. Foamy gland adenocarcinoma of the prostate: incidence, Gleason grade, and early clinical outcome. Hum Pathol 2012;43: 974-979.

56 Zhao J, Epstein JI. High-grade foamy gland prostatic adenocarcinoma on biopsy or TUR: a morphologic study of 55 cases. Am J Surg Pathol 2009;33:583-590.

57 Gikas PW, Del Buono EA, Epstein JI. Florid hyperplasia of mesonephric remnants involving prostate and periprostatic tissue. Possible confusion with adenocarcinoma. Am J Surg Pathol 1993;17:454-460.

58 Bostwick DG, Qian J, Ma J, et al. Mesonephric remnants of the prostate: incidence and histologic spectrum. Mod Pathol 2003;16:630-635.

59 Chen YB, Fine SW, Epstein JI. Mesonephric remnant hyperplasia involving prostate and periprostatic tissue: findings at radical prostatectomy. Am J Surg Pathol 2011;7:1054-1061.

60 Gaudin PB, Wheeler TM, Epstein JI. Verumontanum mucosal gland hyperplasia in prostatic needle biopsy specimens. A mimic of low grade prostatic adenocarcinoma. Am J Clin Pathol 1995;104:620-626.

61 Gagucas RJ, Brown RW, Wheeler TM. Verumontanum mucosal gland hyperplasia. Am J Surg Pathol 1995;19: 30-36.

62 Humphrey PA, Kaleem Z, Swanson PE, Vollmer RT. Pseudohyperplastic prostatic adenocarcinoma. Am J Surg Pathol 1998;22:1239-1246.

63 Levi AW, Epstein JI. Pseudohyperplastic prostatic adenocarcinoma on needle biopsy and simple prostatectomy. Am J Surg Pathol 2000;24:1039-1046.
64 Quick CM, Gokden N, Sangoi AR, et al. The distribution of PAX-2 immunoreactivity in the prostate gland, seminal vesicle, and ejaculatory duct: comparison with prostatic adenocarcinoma and discussion of prostatic zonal embryogenesis. Hum Pathol 2010;41:1145-1149.

65 Leroy X, Ballereau C, Villers A, et al. MUC6 is a marker of seminal vesicle-ejaculatory duct epithelium and is useful for the differential diagnosis with prostate adenocarcinoma. Am J Surg Pathol 2003;27:519-521.

66 Chughtai B, Sawas A, O'Malley RL, et al. A neglected gland: a review of Cowper's gland. Int J Androl 2005;28: 74-77.

67 Saboorian MH, Huffman H, Ashfaq R, et al. Distinguishing Cowper's glands from neoplastic and pseudoneoplastic lesions of prostate: immunohistochemical and ultrastructural studies. Am J Surg Pathol 1997;21: 1069-1074.

68 Cina SJ, Silberman MA, Kahane H, et al. Diagnosis of Cowper's glands on prostate needle biopsy. Am J Surg Pathol 1997;21:550-555.

69 Ostrowski ML, Wheeler TM. Paraganglia of the prostate. Location, frequency, and differentiation from prostatic adenocarcinoma. Am J Surg Pathol 1994;18:412-420.

70 Kawabata K. Paraganglion of the prostate in a needle biopsy: a potential diagnostic pitfall. Arch Pathol Lab Med 1997;121:515-516.

71 Howarth SM, Griffiths DF, Varma M. Paraganglion of the prostate gland: an uncommon mimic of prostate cancer in needle biopsies. Histopathology 2005;47:114-115.

72 Maniar KP, Unger PD, Samadi DB, et al. Incidental prostatic paraganglia in radical prostatectomy specimens: a diagnostic pitfall. Int J Surg Pathol 2011;19: 772-774.

73 Carstens PH. Perineural glands in normal and hyperplastic prostates. J Urol 1980;123:686-688.

74 Cramer SF. Benign glandular inclusion in prostatic nerve. Am J Clin Pathol 1981;75:854-855.

75 McIntire TL, Franzini DA. The presence of benign prostatic glands in perineural spaces. J Urol 1986;135: 507-509.

76 Ali TZ, Epstein JI. Perineural involvement by benign prostatic glands on needle biopsy. Am J Surg Pathol 2005;29:1159-1163.

77 So JS, Epstein JI. Histologic features of pseudohyperplastic perineural invasion in prostatic adenocarcinoma: a mimicker of benign hyperplastic glands and high-grade prostatic intraepithelial neoplasia. Am J Surg Pathol 2014;38:852-857.

78 Schowinsky JT, Epstein JI. Distorted rectal tissue on prostate needle biopsy: a mimicker of prostate cancer. Am J Surg Pathol 2006;30:866-870.

79 Sebo TJ, Bostwick DG, Farrow GM, et al. Prostatic xanthoma: a mimic of prostatic adenocarcinoma. Hum Pathol 1994;25:386-389.

80 Chuang AY, Epstein JI. Xanthoma of the prostate: a mimicker of high-grade prostate adenocarcinoma. Am J Surg Pathol 2007;31:1225-1230.

81 Presti B, Weidner N. Granulomatous prostatitis and poorly differentiated prostate carcinoma. Their distinction with the use of immunohistochemical methods. Am J Clin Pathol 1991;95:330-334.

82 Oppenheimer JR, Kahane H, Epstein JI. Granulomatous prostatitis on needle biopsy. Arch Pathol Lab Med 1997;121:724-729.

83 Alguacil-Garcia A. Artifactual changes mimicking signet ring cell carcinoma in transurethral prostatectomy specimens. Am J Surg Pathol 1986;10:795-800. 
84 Wang HL, Humphrey PA. Exaggerated signet-ring cell change in stromal nodule of prostate: a pseudoneoplastic proliferation. Am J Surg Pathol 2002;26: 1066-1070.

85 Sarma HN, Ramesh K, al Fituri O, et al. Malakoplakia of the prostate gland-report of two cases and review of the literature. Scand J Urol Nephrol 1996;30:155-157.

86 Agostinho AD, Correa LA, Amaro JL, et al. Malacoplakia or prostate cancer? Similarities and differences. Urol Int 1998;61:47-49.
87 Repassy DL, Ivanyi A, Csata S, et al. Combined occurrence of prostate carcinoma and malacoplakia. Pathol Oncol Res 2002;8:202-203.

88 Wagner D, Joseph J, Huang J, et al. Malakoplakia of the prostate on needle core biopsy: a case report and review of the literature. Int J Surg Pathol 2007;15:86-89.

89 Medlicott S, Magi-Galluzzi C, Jimenez RE, et al. Malakoplakia associated with prostatic adenocarcinoma: report of 4 cases and literature review. Ann Diagn Pathol 2016;22:33-37. 